Article

\title{
Conformation and Domain Movement Analysis of Human Matrix Metalloproteinase-2: Role of Associated $\mathrm{Zn}^{2+}$ and $\mathrm{Ca}^{2+}$ Ions
}

\author{
Leah Voit-Ostricki ${ }^{1}$, Sándor Lovas ${ }^{2}$ and Charles R. Watts ${ }^{1,3, *(\mathbb{C}}$ \\ 1 Department of Neurosurgery, Mayo Clinic Health System-Franciscan Healthcare, La Crosse, WI 54601 USA \\ 2 Department of Biomedical Sciences, Creighton University, Omaha, NE 68178, USA \\ 3 Department of Neurologic Surgery, Mayo Clinic, Rochester, MN 55905, USA \\ * Correspondence: charles.watts@parknicollet.com; Tel.: +1-952-993-3200; Fax: +1-952-993-7407
}

Received: 3 July 2019; Accepted: 26 August 2019; Published: 27 August 2019

check for updates

\begin{abstract}
Matrix metaloproteinase-2 (MMP-2) is an extracellular $\mathrm{Zn}^{2+}$ protease specific to type I and IV collagens. Its expression is associated with several inflammatory, degenerative, and malignant diseases. Conformational properties, domain movements, and interactions between MMP-2 and its associated metal ions were characterized using a $1.0 \mu$ s molecular dynamics simulation. Dihedral principle component analysis revealed ten families of conformations with the greatest degree of variability occurring in the link region connecting the catalytic and hemopexin domains. Dynamic cross-correlation analysis indicated domain movements corresponding to the opening and closing of the hemopexin domain in relation to the fibronectin and catalytic domains facilitated by the link region. Interaction energies were calculated using the molecular mechanics Poisson Boltzman surface area-interaction entropy (MMPBSA-IE) analysis method and revealed strong binding energies for the catalytic $\mathrm{Zn}^{2+}$ ion $1, \mathrm{Ca}^{2+}$ ion 1 , and $\mathrm{Ca}^{2+}$ ion 3 with significant conformational stability at the binding sites of $\mathrm{Zn}^{2+}$ ion 1 and $\mathrm{Ca}^{2+}$ ion $1 . \mathrm{Ca}^{2+}$ ion 2 diffuses freely away from its crystallographically defined binding site. $\mathrm{Zn}^{2+}$ ion 2 plays a minor role in conformational stability of the catalytic domain while $\mathrm{Ca}^{2+}$ ion 3 is strongly attracted to the highly electronegative sidechains of the Asp residues around the central $\beta$-sheet core of the hemopexin domain; however, the interacting residue sidechain carboxyl groups are outside of $\mathrm{Ca}^{2+}$ ion $3^{\prime} \mathrm{s}$ coordination sphere.
\end{abstract}

Keywords: molecular dynamics; matrix metalloproteinase; domain movement; zinc binding protein; calcium binding protein

\section{Introduction}

Matrix metaloproteinase-2 (MMP-2) is a 550 amino acid residue extracellular $\mathrm{Zn}^{2+}$ protease that degrades type I and IV collagens [1,2]. It is related to a family of 24 known endopeptidases with an active site $\mathrm{Zn}^{2+}$ ion. On the basis of evolutionary relationships and the structure of their domains, the family is divided into four subfamilies [3-5]. MMP-2 expression is associated with normal physiology, as well as several inflammatory, degenerative, and malignant diseases [6-12]. As shown in Figure 1; MMP-2 has three domains, catalytic (Cat), fibronectin (Fib), and hemopexin (Hpx) and five crystallographically assigned divalent cations (two $\mathrm{Zn}^{2+}$ and three $\mathrm{Ca}^{2+}$ ) [13]. The Cat domain $\left(\mathrm{Tyr}^{110}\right.$ through $\mathrm{Tyr}^{445}$ ) is a conserved matrixin fold consisting of five $\beta$-sheets and three $\alpha$-helices. The Fib domain $\left(\mathrm{Glu}^{217}\right.$ through $\left.\mathrm{Gln}^{393}\right)$ is inserted within the catalytic domain between the $\beta 5$-sheet and $\alpha 2$-helix and contains three type II fibronectin fingers consisting of two antiparallel $\beta$-sheets connected by a short $\alpha$-helix forming a three prong treble hook-like arrangement. This domain and its arrangement may play a crucial role in substrate binding and presentation to the catalytic site. The Hpx 
domain $\left(\right.$ Leu $^{461}$-Cys $^{660}$ ) is a four bladed propeller fold that is partially oriented toward the catalytic domain. This domain binds an endogenous inhibitor TIMP-2; however, its role in enzymatic function is unknown. The Hpx and Cat domains are connected by a 16 amino acid proline rich Lnk region $\left(\right.$ Gly ${ }^{446}$ through $\mathrm{Thr}^{460}$ ) which is unresolved in the 1CK7 X-ray crystal structure and has been shown to be highly flexible in other molecular dynamics investigations $[14,15]$.
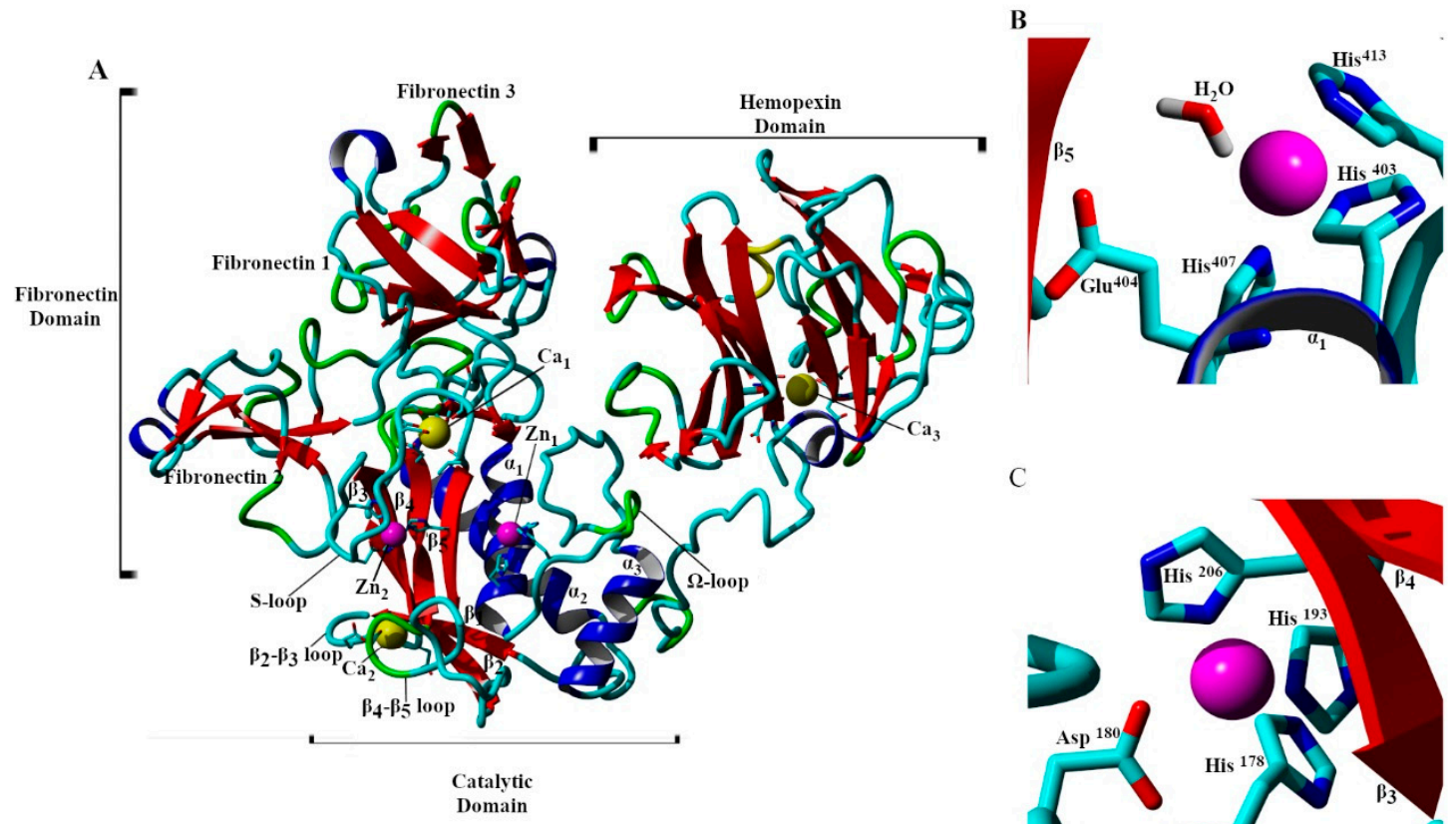

$\mathrm{D}$

E
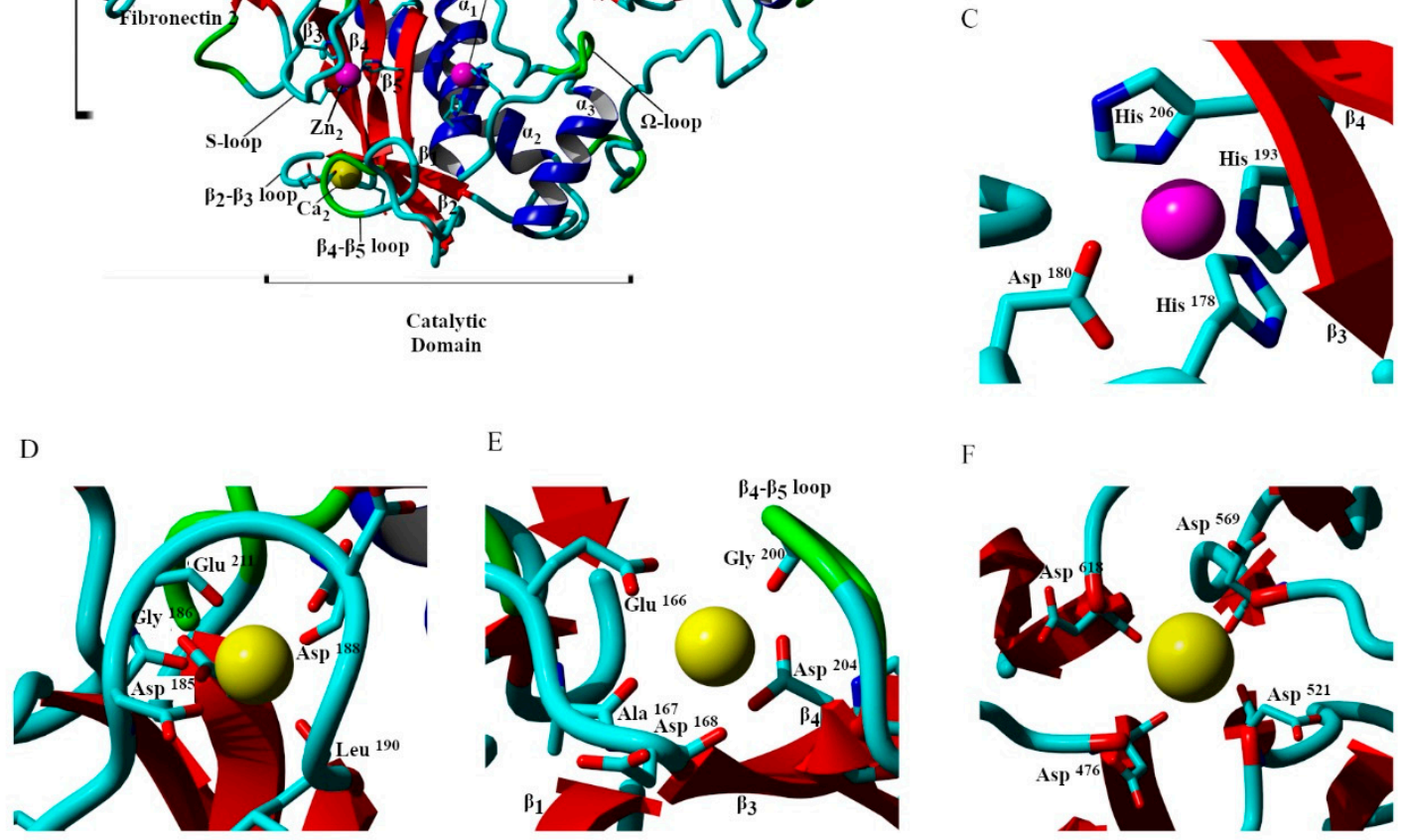

$\mathrm{F}$

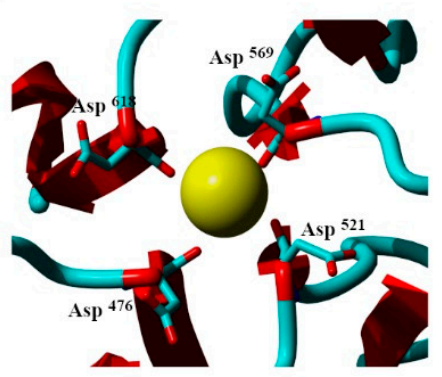

Figure 1. The ribbon diagram of the X-ray crystal structure of $1 C K 7$. The pro-peptide (Pro ${ }^{31}-\mathrm{Gln}^{109}$ ) region is removed, and the unresolved link $\left(\mathrm{Asp}^{450}-\mathrm{Thr}^{460}\right.$ ) connecting the Cat and Hpx domains built with YASARA [16]. Domains, subdomains, and secondary structural features of the catalytic domain are labeled accordingly (blue, $\alpha$-helix; red, $\beta$-sheet; green, $\beta$-turn/bend; and aqua, coil) (A). The associated ions are shown as van der Waals radii with $\mathrm{Zn}^{2+}$ pink and $\mathrm{Ca}^{2+}$ yellow. The catalytic $\mathrm{Zn}^{2+}$ ion 1 is bound to $\mathrm{His}^{403}, \mathrm{Glu}^{404}, \mathrm{His}^{407}, \mathrm{His}^{413}$, and catalytic water (B). $\mathrm{Zn}^{2+}$ ion 2 is bound to His $^{178}, \mathrm{Asp}^{180}$, His ${ }^{193}$, and His ${ }^{206}$ (C). Ca ${ }^{2+}$ ion 1 is bound to Asp ${ }^{185}, \mathrm{Gly}^{186}$, Asp ${ }^{188}$, Leu ${ }^{198}$, Asp ${ }^{208}$, and $\mathrm{Glu}^{211}$ (D). $\mathrm{Ca}^{2+}$ ion 2 is bound to $\mathrm{Glu}^{166}, \mathrm{Ala}^{167}, \mathrm{Asp}^{168}, \mathrm{Gly}^{200}, \mathrm{Gly}^{202}$, and $\mathrm{Asp}^{204}$ (E). Ca ${ }^{2+}$ ion 3 is bound to Asp ${ }^{476}, \mathrm{Asp}^{521}, \mathrm{Asp}^{569}$, and $\mathrm{Asp}^{618}(\mathbf{F})$.

Coordination geometries and interatomic metal cation to MMP-2 residue distances from the 1 CK7 X-ray crystal structure are given in Table $1[13,17,18]$. The catalytic $\mathrm{Zn}^{2+}$ ion 1 is bound by the conserved MMP extended zinc binding motif [5]: 
which in MMP-2 consists of interactions between the divalent cation and the sidechains of $\mathrm{His}^{403}$ and $\mathrm{His}^{407}$ from the $\alpha$-helix, and His ${ }^{413}$ from the $\Omega$-loop (Figure 1B). The structural $\mathrm{Zn}^{2+}$ ion 2 is bound in a trigonal bipyramidal arrangement involving the sidechains of $\mathrm{His}^{193}$ and $\mathrm{His}^{206}$ from the $\beta 5$ - and $\beta 4$-sheets respectively and Asp ${ }^{180}$ and His ${ }^{178}$ of the long S-loop of the Cat domain which is a conserved motif in the MMP family (Figure 1C). Two of the $\mathrm{Ca}^{2+}$ ions are bound near the Cat domain with $\mathrm{Ca}^{2+}$ ion 1 bound by the sidechains of $\mathrm{Asp}^{208}$ and $\mathrm{Glu}^{211}$ of the interim loop connecting the Cat and Fib domains and the carbonyl oxygens of $\mathrm{Asp}^{185}, \mathrm{Gly}^{186}, \mathrm{Asp}^{188}$, and Leu ${ }^{190}$ of the loop connecting the $\beta 3$ - and $\beta 5$-sheets (Figure 1D). $\mathrm{Ca}^{2+}$ ion 2 is bound by the sidechains of $\mathrm{Glu}^{166}$ and carbonyl oxygens of Ala ${ }^{167}$ and Asp ${ }^{168}$ arising from the loop connecting the $\beta 1$ - and $\beta 3$-sheets, the carbonyl oxygen of $\mathrm{Gly}^{200}$ of the loop connecting $\beta 5$ - and $\beta 4$-sheets, and the sidechain of Asp ${ }^{204}$ arising from the $\beta 4$-sheet, Figure 1E. The third structural $\mathrm{Ca}^{2+}$ ion 3, is bound by the carbonyl oxygens of $\mathrm{Asp}^{476}, \mathrm{Asp}^{521}, \mathrm{Asp}^{569}$, and $\mathrm{Asp}^{618}$ at the edge of the central cavity of the Hpx domain (Figure 1F).

Table 1. Distances between ions and the interacting matrix metaloproteinase-2 (MMP-2) residue atoms and associated binding geometry identified from the 1CK7 X-ray crystal structure. Binding geometries and distances were determined using CheckMyMetal ${ }^{\mathrm{a}, \mathrm{b}, \mathrm{c}}$.

\begin{tabular}{|c|c|c|c|c|c|c|}
\hline \multirow[b]{2}{*}{ Protein Atom } & \multirow{2}{*}{ Geometry } & \multicolumn{5}{|c|}{ Distance/nm } \\
\hline & & $\mathrm{Zn}^{2+}$ ion 1 & $\mathrm{Zn}^{2+}$ ion 2 & $\mathrm{Ca}^{2+}$ ion 1 & $\mathrm{Ca}^{2+}$ ion 2 & $\mathrm{Ca}^{2+}$ ion 3 \\
\hline $\mathrm{His}^{403}: \mathrm{N} \varepsilon 2$ & tetrahedral & 0.23 & & & & \\
\hline $\mathrm{His}^{407}: \mathrm{N} \varepsilon 2$ & tetrahedral & 0.22 & & & & \\
\hline $\mathrm{His}^{413}: \mathrm{N} \varepsilon 2$ & tetrahedral & 0.25 & & & & \\
\hline Water:O & tetrahedral & 0.25 & & & & \\
\hline $\mathrm{Glu}^{404}: \mathrm{O} \varepsilon 1$ & & 0.83 & & & & \\
\hline $\mathrm{Glu}^{404}: \mathrm{O} \varepsilon 2$ & & 0.76 & & & & \\
\hline $\mathrm{His}^{178}: \mathrm{N} \varepsilon 2$ & trigonal bipyramidal & & 0.21 & & & \\
\hline $\mathrm{Asp}^{180}: \mathrm{O} \delta 2$ & trigonal bipyramidal & & 0.23 & & & \\
\hline His $^{193}: \mathrm{N} \varepsilon 2$ & trigonal bipyramidal & & 0.21 & & & \\
\hline $\mathrm{His}^{206}: \mathrm{N} \delta 1$ & trigonal bipyramidal & & 0.21 & & & \\
\hline $\operatorname{Asp}^{185}: C=O$ & octahedral & & & 0.29 & & \\
\hline Gly ${ }^{186}: C=O$ & octahedral & & & 0.24 & & \\
\hline Asp $^{188}: C=O$ & octahedral & & & 0.26 & & \\
\hline Leu $^{198}: \mathrm{C}=\mathrm{O}$ & octahedral & & & 0.25 & & \\
\hline $\mathrm{Asp}^{208}: \mathrm{O} \delta 2$ & octahedral & & & 0.25 & & \\
\hline $\mathrm{Glu}^{211}: \mathrm{O} \varepsilon 2$ & octahedral & & & 0.27 & & \\
\hline $\mathrm{Ala}^{167}: \mathrm{C}=0$ & poorly coordinated & & & & 0.29 & \\
\hline Asp $^{168}: C=O$ & poorly coordinated & & & & 0.29 & \\
\hline Gly $^{200}: C=O$ & poorly coordinated & & & & 0.27 & \\
\hline $\operatorname{Asp}^{476}: C=O$ & square planar & & & & & 0.25 \\
\hline $\operatorname{Asp}^{521}: C=O$ & square planar & & & & & 0.28 \\
\hline Asp $^{569}: C=O$ & square planar & & & & & 0.27 \\
\hline Asp $^{618}: C=O$ & square planar & & & & & 0.27 \\
\hline
\end{tabular}

The goal of the current study is to evaluate the dynamic stability of the divalent metal ions $\left(2 \mathrm{Zn}^{2+}\right.$ and $3 \mathrm{Ca}^{2+}$ ) reported in the X-ray crystal structure protein databank (PDB) ID: 1CK7 and examine the domain movements within MMP-2 using $1.0 \mu \mathrm{s}$ NPT molecular dynamics (MD) simulations at physiological temperature $(310 \mathrm{~K})$. Protein-metal cation distances and MMPBSA-interaction entropy binding energies $(\Delta G)$ were calculated, and the sampled conformational space analyzed with dihedral Principle Component Analysis (dPCA) and Dynamic Cross-Correlation Matrix (DCCM) analysis. The stability of the divalent ions and domain movement conformations will play an important role in the development of an additive force field model for protein-ligand docking studies, subsequent dynamic protein-ligand simulations and potential MMP-2 inhibitor development. 


\section{Results and Discussion}

\subsection{System Equilibration and Conformational Stability}

The $C \alpha$-trace configurational entropy of MMP-2 and associated divalent ions was calculated as a function of time (Figure S1) [19-21]. After a sharp rise in the configurational entropy over the first $100 \mathrm{~ns}$, the value plateaus prior to $200 \mathrm{~ns}$. Based on these results, we used the $200 \mathrm{~ns}$ to $1000 \mathrm{~ns}$ portion of the trajectory for our analysis with a sampling frequency of $0.1 \mathrm{~ns}$. The radius of gyration $\left(\mathrm{R}_{\mathrm{g}}\right)$ and inter-domain center-of mass (COM) distances: Cat-Hpx and Fib-Hpx, were analyzed with $\mathrm{k}$-means clustering and the associated means and standard deviations of each population calculated (Figures S2 and S3) [22,23]. Due to the large changes in $\mathrm{R}_{\mathrm{g}}$ and COM distances between the domains and to ensure that the size of the solvation box was adequate, the minimum distances between periodic images as a function of simulation time were determined using the g_mindist utility in GROMACS (periodic minimum distance: $3.81 \pm 0.75 \mathrm{~nm}$ ). Five different distributions of protein conformations were identified with $R_{\mathrm{g}}: 2.65 \pm 0.02 \mathrm{~nm}, 2.70 \pm 0.06 \mathrm{~nm}, 2.80 \pm 0.05 \mathrm{~nm}, 2.83 \pm 0.04 \mathrm{~nm}$, and $3.09 \pm 0.13 \mathrm{~nm}$. The COM distances mirror the $\mathrm{R}_{\mathrm{g}}$ results, identifying five distributions of Cat-Hpx COM distances: $3.55 \pm 0.10 \mathrm{~nm}, 3.70 \pm 0.17 \mathrm{~nm}, 3.79 \pm 0.06 \mathrm{~nm}, 3.86 \pm 0.13 \mathrm{~nm}$, and $4.20 \pm 0.23 \mathrm{~nm}$. Five distributions of Fib-Hpx COM distances: $3.70 \pm 0.06 \mathrm{~nm}, 3.84 \pm 0.18 \mathrm{~nm}, 4.32 \pm 0.22 \mathrm{~nm}, 4.48 \pm 0.18 \mathrm{~nm}$, and $5.52 \pm 0.48 \mathrm{~nm}$, were also identified. The $\mathrm{R}_{\mathrm{g}}$ and COM distance data are consistent with inter-domain motions between $\mathrm{Cat} / \mathrm{Fib}$ and Hpx and the presence of inter-domain motions and the sampling of more extended conformations of MMP-2 in solution compared to the more compact X-ray crystal structure (PDB ID: 1CK7) which has $\mathrm{R}_{\mathrm{g}}: 2.77 \mathrm{~nm}$, Cat-Hpx COM distance: $3.81 \mathrm{~nm}$, and Fib-Hpx COM distance: $2.00 \mathrm{~nm}$ [13]. These values are also consistent with those determined from prior simulations using the AMBER param03 force field [14,15]. It is not clear from either previous (multiple $200 \mathrm{~ns}$ simulations) or the current $(1.0 \mu \mathrm{s})$ simulation if more extended conformations may be sampled or if an opening and closing of the Cat/Fib to Hpx domains occurs over longer time scales [14,15].

The average $\mathrm{C} \alpha$-trace root mean square deviation (RMSD) data for MMP-2 as a whole and divided into its individual domains are given in Table 2. The most conformationally stable regions of the protein are the Cat and Hpx domains as observed in previous simulations with the majority of the C $\alpha$-trace flexibility accounted for within the three Fib domain, particularly the individual subdomains [14,15]. Although the RMSD of the Lnk region is low and comparable to that of Cat and Hpx, it should be considered that this is only a short 15 amino acid segment and that minor variations in the $\phi / \psi$ dihedral angles can result in dramatic changes in the relationships between the Cat and Hpx domains [15]. The $C \alpha$-trace root mean square fluctuation (RMSF) with the secondary structure assigned by the database of secondary structure assignments in the protein databank (DSSP) method is shown in Figure 2 [24]. Those regions with defined rigid secondary structure ( $\beta$-sheets and $\alpha$-helices) have lower RMSF values compared to more flexible $\beta$-turn/bend and coil regions. The greatest degree of conformational variability occurs within the Fib domain, while the most stable regions of the protein are within the Cat and Hpx domains. The stability of the Cat and Hpx domains is most likely secondary to the presence of the three long $\alpha$-helices of the Cat domain and the prominent $\beta$-sheets and ordered arrangement of the Hpx domain. Although the ordered secondary structure is present within the Fib domain, it consists of three separate subdomains with a significant portion of the fold consisting of flexible $\beta$-turn/bend and coils. Flexibility within the treble hook arrangement of the Fib domain may play an important role in collagen binding and unraveling [25-28].

Table 2. Average root mean square deviation (RMSD) of the $\mathrm{C} \alpha$-trace of MMP-2 as a whole and divided into its individual domains: Cat, Fib, and Hpx with the Lnk region ${ }^{\mathrm{a}, \mathrm{b}}$.

\begin{tabular}{ccccccc}
\hline & All & Cat w/ Fib & Fib & Cat w/o Fib & Hpx & Lnk \\
\hline RMSD/nm & $3.20 \pm 0.14$ & $3.34 \pm 0.02$ & $3.69 \pm 0.03$ & $0.50 \pm 0.03$ & $0.34 \pm 0.04$ & $0.54 \pm 0.08$ \\
\hline \multicolumn{7}{c}{${ }^{\mathrm{a}}$ w/ is with $^{\mathrm{b}}$ w/o is without. }
\end{tabular}




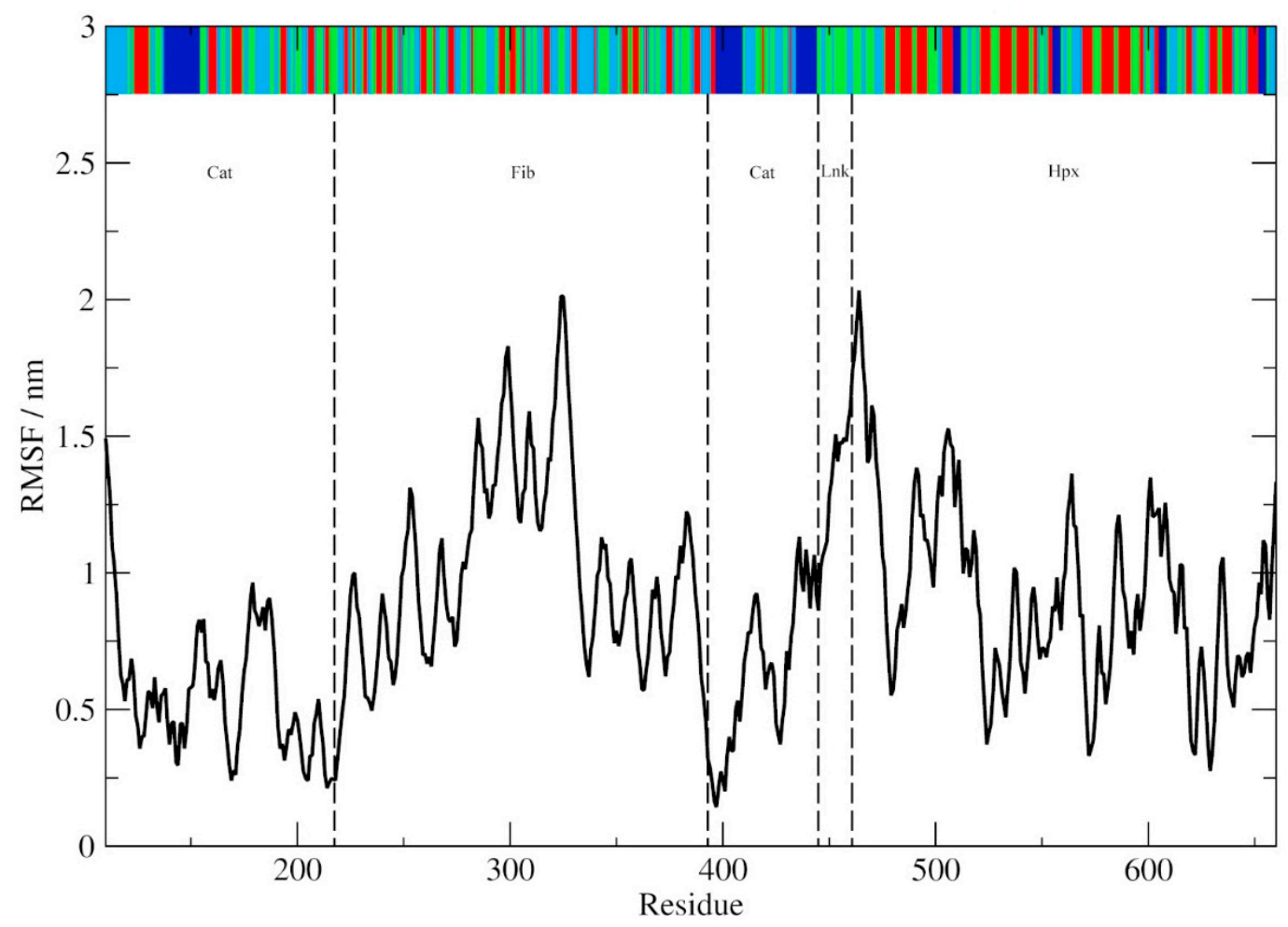

Figure 2. The $\mathrm{C} \alpha$-trace root mean square fluctuation (RMSF). The DSSP assigned secondary structure (sampled $>50 \%$ of the simulation time) is shown at the top of the graph (blue, $\alpha$-helix; red, $\beta$-sheet; green, $\beta$-turn/bend; and aqua, coil). The Cat, Fib and Hpx domains and Lnk regions are demarcated with dotted lines.

\subsection{Conformational Analysis}

The free energy landscape created by the first two dihedral principle components (dPC) is shown in Figure 3, with the corresponding lowest energy centroid conformations as determined by k-means clustering. The most conformationally stable region is the Cat domain in which the active site $\mathrm{Zn}^{2+}$ ion 1 is bound by His residues of the $\alpha 1$-helix and the $\Omega$-loop (Figures 3 and 4 ). The structure around $\mathrm{Ca}^{2+}$ ion 1 also is stable with the cation bound within a pocket created by the distal portion of the S-loop and the interim loop connecting the Cat and Fib domains. This stability is also confirmed by the low RMSD and RMSF values for the Cat domain and those of $\mathrm{Zn}^{2+}$ ion 1 and $\mathrm{Ca}^{2+}$ ion 1 with both ions staying closely associated with the Cat domain of the protein and approximate to their crystallographically defined positions during the simulation (Tables 2 and 3 and Figures 3 and 4). The other associated metal ions of the Cat domain do not share this degree of stability (Table 3). $\mathrm{Zn}^{2+}$ ion 2 remains associated with the S-loop, but loses contact with the crystallographically demonstrated interactions with the His residues on the $\beta 4$ - and $\beta 5$-sheets. This may not be unexpected, since conformational flexibility within the S-loop region, as was reported previously [29] and may allow for changes in the binding pocket conformation necessary for substrate recognition. $\mathrm{Ca}^{2+}$ ion 2 does not remain in close contact with the $\beta 1-\beta 3-$ loop and diffuses out of the binding pocket (Figures 3 and 4). The Hpx associated $\mathrm{Ca}^{2+}$ ion 3 remains close to its crystallographically observed binding site (Figures 3 and 4) with a relatively low RMSF (Table 3), but to a lower degree that either $\mathrm{Zn}^{2+}$ ion $1 \mathrm{or} \mathrm{Ca}^{2+}$ ion 1 .

The majority of the conformational fluctuations within MMP-2 are within the Fib domain (Figures 3 and 4 and Table 2). The three type II Fib subdomains are highly flexible, partly due to the large amount of $\beta$-turn/bend and coil structure within the subdomains. This degree of flexibility may be important for interactions between MMP-2 and its collagen substrates [25-28]. There is also clearly an inter-domain interaction that occurs between Hpx and the Cat and Fib domains mediated by the Lnk region. The Lnk region acts as a complex hinge allowing the COM distance between the Cat/Fib and 
Hpx domains to open and close while changing the orientation of the Hpx domain from an edge view to an end on view (Figure 3). This rotation of the Hpx domain in relation to the Cat domain has also been noted in prior simulations [14,15].

The radial distribution functions for the $\mathrm{Zn}^{2+}$ ions demonstrated peaks at $0.20 \mathrm{~nm}$ and $0.42 \mathrm{~nm}$ with troughs located at $0.31 \mathrm{~nm}$ and $0.50 \mathrm{~nm}$. The $\mathrm{Ca}^{2+}$ ions have slightly enlarged the first and second hydration shells, with peaks at 0.25 and $0.44 \mathrm{~nm}$, and troughs at $0.31 \mathrm{~nm}$ and $0.55 \mathrm{~nm}$, respectively. The statistical densities of the first and second hydration shells ( $\rho$ (1st shell) and $\rho$ (2nd shell)) are given in Table 4 . These values represent the probabilities of a water molecule(s) occupying the volume of the hydration shell at any sampled time during the trajectory. There is only a minor difference in the 1st hydration shell comparing $\mathrm{Zn}^{2+}$ ion 1 and $\mathrm{Zn}^{2+}$ ion 2 with more significant changes in the 2nd hydration shell. This is consistent with $\mathrm{Zn}^{2+}$ ion 1 sequestered within the catalytic pocket of the enzyme while $\mathrm{Zn}^{2+}$ ion 2 dissociates from His ${ }^{178}$, $\mathrm{His}^{193}$, and $\mathrm{His}^{206}$ and interacting with Asp ${ }^{180}$ on the flexible S-loop. These results are also consistent with the solvent accessible surface area (SASA) which is much lower for $\mathrm{Zn}^{2+}$ ion 1 than $\mathrm{Zn}^{2+}$ ion 2. The results for the $\mathrm{Ca}^{2+}$ ions demonstrate that $\mathrm{Ca}^{2+}$ ion 1 is solvent sequestered with a low probability of water within the first hydration shell. $\mathrm{Ca}^{2+}$ ion 2 which dissociates from its binding site early in the simulation and appears to diffuse freely is similar the $\mathrm{Ca}^{2+}$ ion 3 which stays in closer proximity to the Hpx domain, but does not stay in close contact with its crystallographically associated residues. The SASA values in Table 4 also reflect this. The coordination numbers $(\mathrm{CN})$ for the ions are given below. The value of 1 to 1.5 for $\mathrm{Zn}^{2+}$ ion 1 is consistent with prior studies [30,31]. The CN was also be calculated for $\mathrm{Glu}^{404}$ and is equal 1 , in agreement with this residue's catalytic importance and its proximity to the catalytic $\mathrm{Zn}^{2+}$ ion 1 . The sequestered nature of $\mathrm{Ca}^{2+}$ ion 1 indicates only one associated water molecule while $\mathrm{Ca}^{2+}$ ion 2 and $\mathrm{Ca}^{2+}$ ion 3 are more normally hydrated.

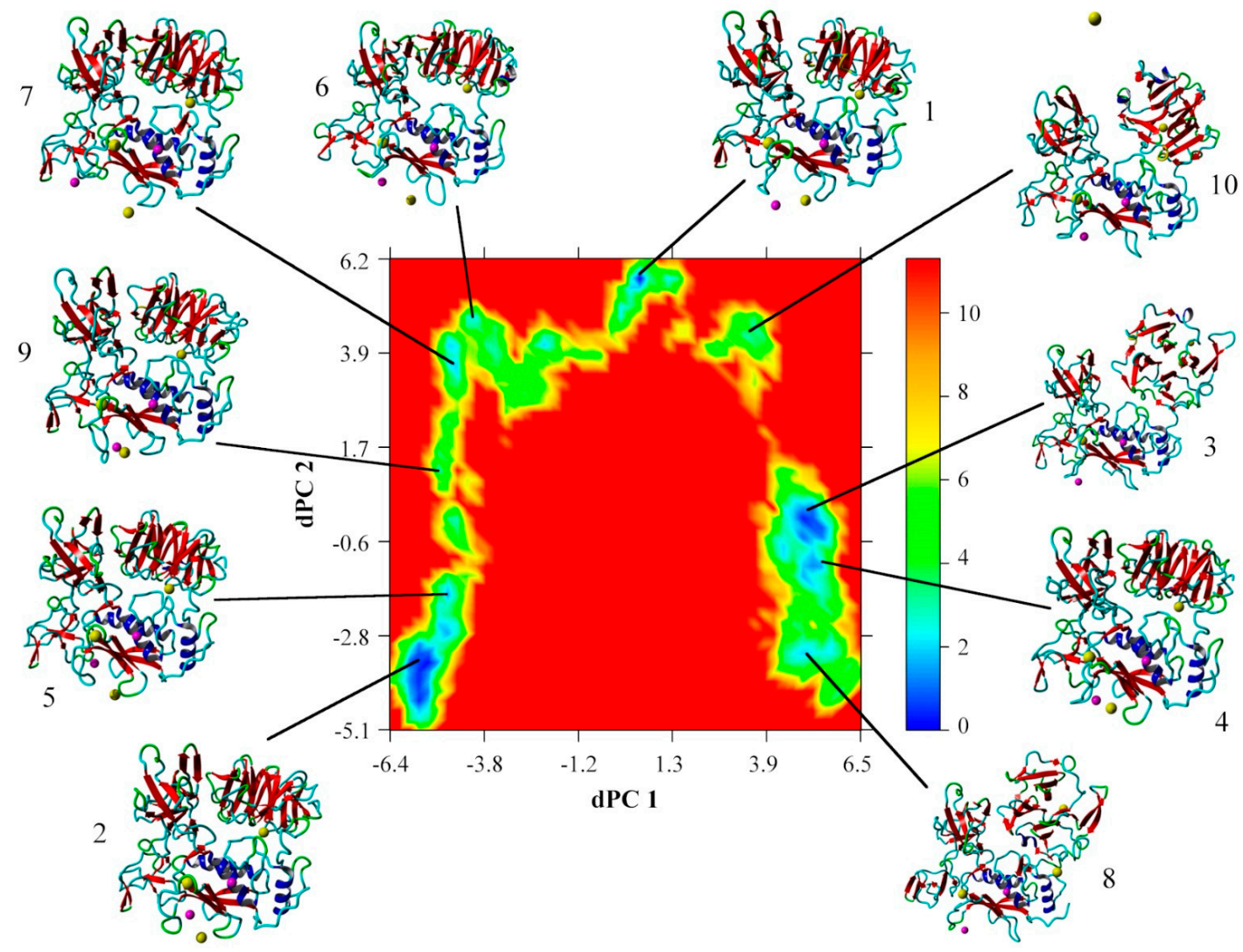

Figure 3. Free energy landscape $\left(\mathrm{kJ} \mathrm{mol}^{-1}\right)$ as a function of the first two dihedral principle components (dPC1 and dPC2); the lowest energy conformations of each family as identified by k-means clustering are shown. Secondary structural motifs and ions are shown (blue, $\alpha$-helix; red, $\beta$-sheet; green, $\beta$-turn/bend; aqua, coil; pink, $\mathrm{Zn}^{2+}$; and yellow, $\mathrm{Ca}^{2+}$ ). 


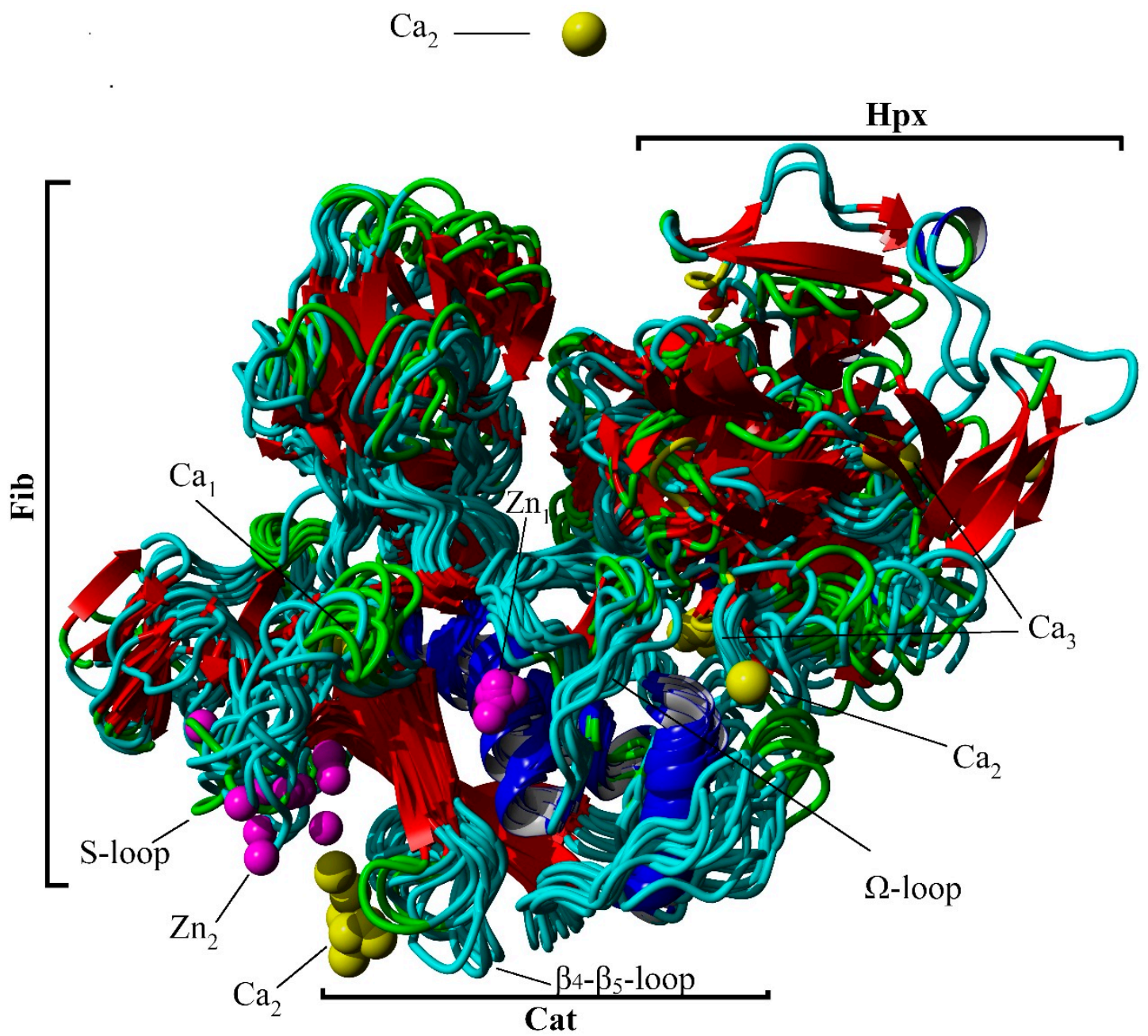

Figure 4. $\mathrm{C} \alpha$-trace overlay of 10 cluster centroid structures from the cluster analysis of dPC1 and dPC2. Secondary structural motifs and ions are shown (blue, $\alpha$-helix; red, $\beta$-sheet; green, $\beta$-turn/bend; aqua, coil; pink, $\mathrm{Zn}^{2+}$; and yellow, $\mathrm{Ca}^{2+}$ ).

Table 3. Average RMSF of the associated divalent cations to the C $\alpha$-trace of MMP- ${ }^{a}$.

\begin{tabular}{cccccc}
\hline & $\mathbf{Z n}^{2+}$ ion $\mathbf{1}$ & $\mathbf{Z n}^{2+}$ ion $\mathbf{2}$ & $\mathbf{C a}^{2+}$ ion $\mathbf{1}$ & $\mathbf{C a}^{2+}$ ion $\mathbf{2}$ & $\mathbf{C a}^{2+}$ ion 3 \\
\hline $\mathrm{RMSF} / \mathrm{nm}$ & 0.593 & 0.882 & 0.571 & 2.906 & 1.062 \\
\hline \multicolumn{5}{c}{${ }^{\mathrm{a}} \mathrm{Zn}^{2+}$ ion 1 is the catalytic ion. }
\end{tabular}

Table 4. Solvation properties of the associated divalent cations. SASA, solvent exposed surface area.

\begin{tabular}{cccccc}
\hline Property & $\mathbf{Z n}^{2+}$ ion $\mathbf{1}$ & $\mathbf{Z n}^{2+}$ ion $\mathbf{2}$ & $\mathbf{C a}^{2+}$ ion $\mathbf{1}$ & $\mathbf{C a}^{2+}$ ion $\mathbf{2}$ & $\mathbf{C a}^{2+}$ ion $\mathbf{3}$ \\
\hline $\boldsymbol{\rho}$ (1st shell) & 0.20 & 0.26 & 0.07 & 0.23 & 0.25 \\
$\boldsymbol{\rho}$ (2nd shell) & 0.29 & 0.41 & 0.22 & 0.44 & 0.41 \\
$\mathbf{S A S A} / \mathbf{n m}^{2}$ & $0.002 \pm 0.010$ & $0.046 \pm 0.030$ & $0.021 \pm 0.013$ & $0.311 \pm 0.110$ & $0.302 \pm 0.119$ \\
$\mathbf{C N}$ & 1 to 2 & 2 & 1 & 3 & 3 \\
\hline
\end{tabular}

${ }^{\mathrm{a}} \rho$ is the statistical density of the hydration shell; ${ }^{\mathrm{b}} \mathrm{SASA}$ is the solvent accessible surface area; ${ }^{\mathrm{c}} \mathrm{CN}$ is the coordination number. 


\subsection{Domain Movement Analysis}

DCCM (Figure 5) demonstrated that motions within Cat, Fib and Hpx domains and Lnk region are, for the most part, highly correlated with a few exceptions. The first five principle components (PC) account for a total of $93.7 \%$ of the total domain motions (Figure 6). The plots of the C $\alpha$-trace RMSF of the projection of the trajectory onto the first five eigenvectors are shown (Figure S4). For PC1, the majority of the contributions arises from the first two subdomains of Fib, the Hpx domains and Lnk region. PC2, has significant motions in the third subdomain of Fib and Hpx. There are also anti-correlated motions with the Cat domain involving the $\alpha 1$-helix and $\beta 1$ - through $\beta 5$-sheets that contain the active site. Motions along PC3 through PC5 represent minor fluctuations within the domains and global conformation. The distal portion of the Cat domain which contains the active site has correlated motions with the first and third subdomains of the Fib domain and the first and second blades of the Hpx domain. There are also anti-correlated motions between the active site on the Cat domain and the second subdomain of the Fib domain and the third and fourth blades of the Hpx domain.

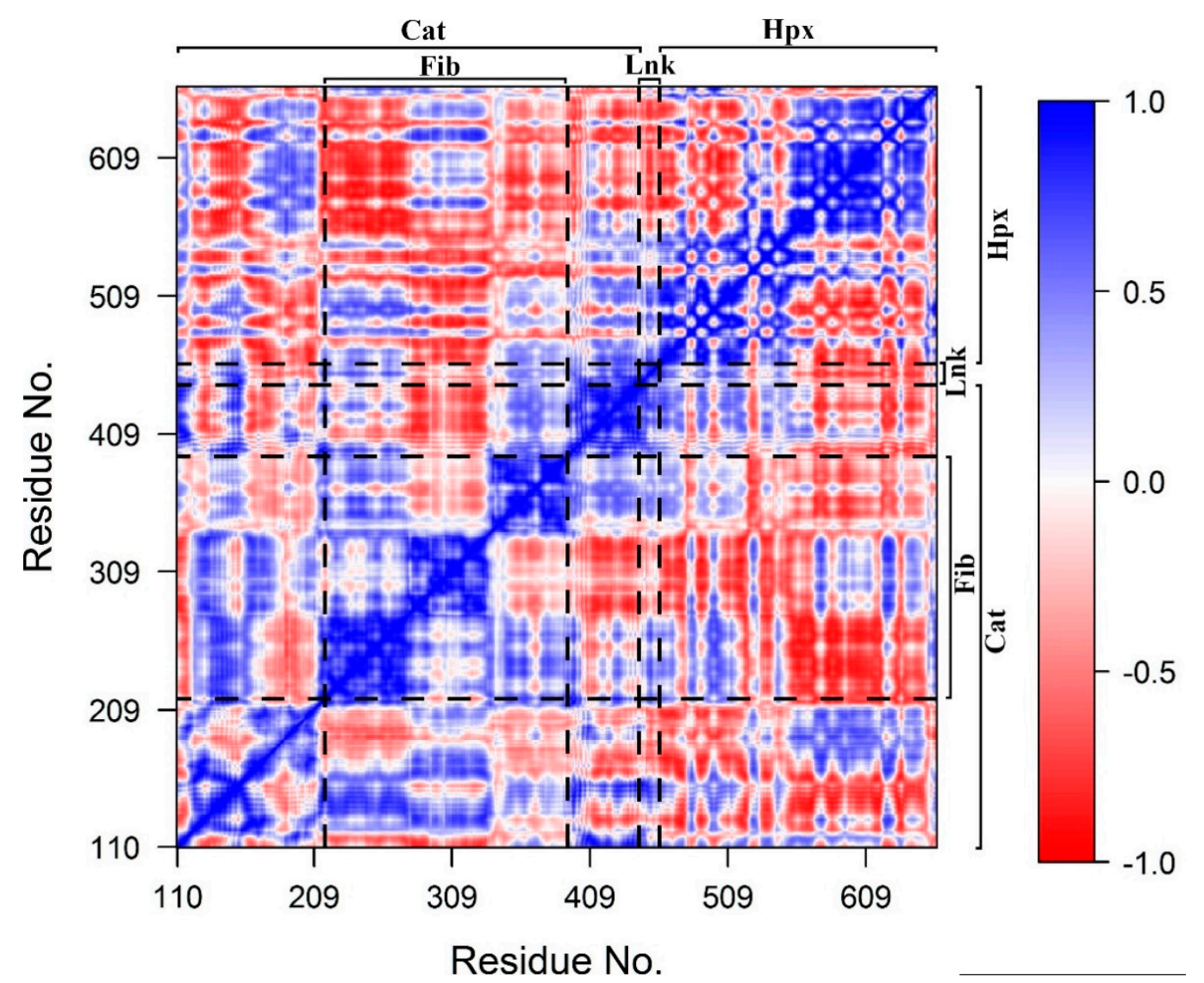

Figure 5. Dynamic cross-correlation matrix. Values range from -1 (complete anti-correlation) to +1 (complete correlation). The Cat, Fib, and Hpx domains and Lnk regions are demarcated with dashed lines. 

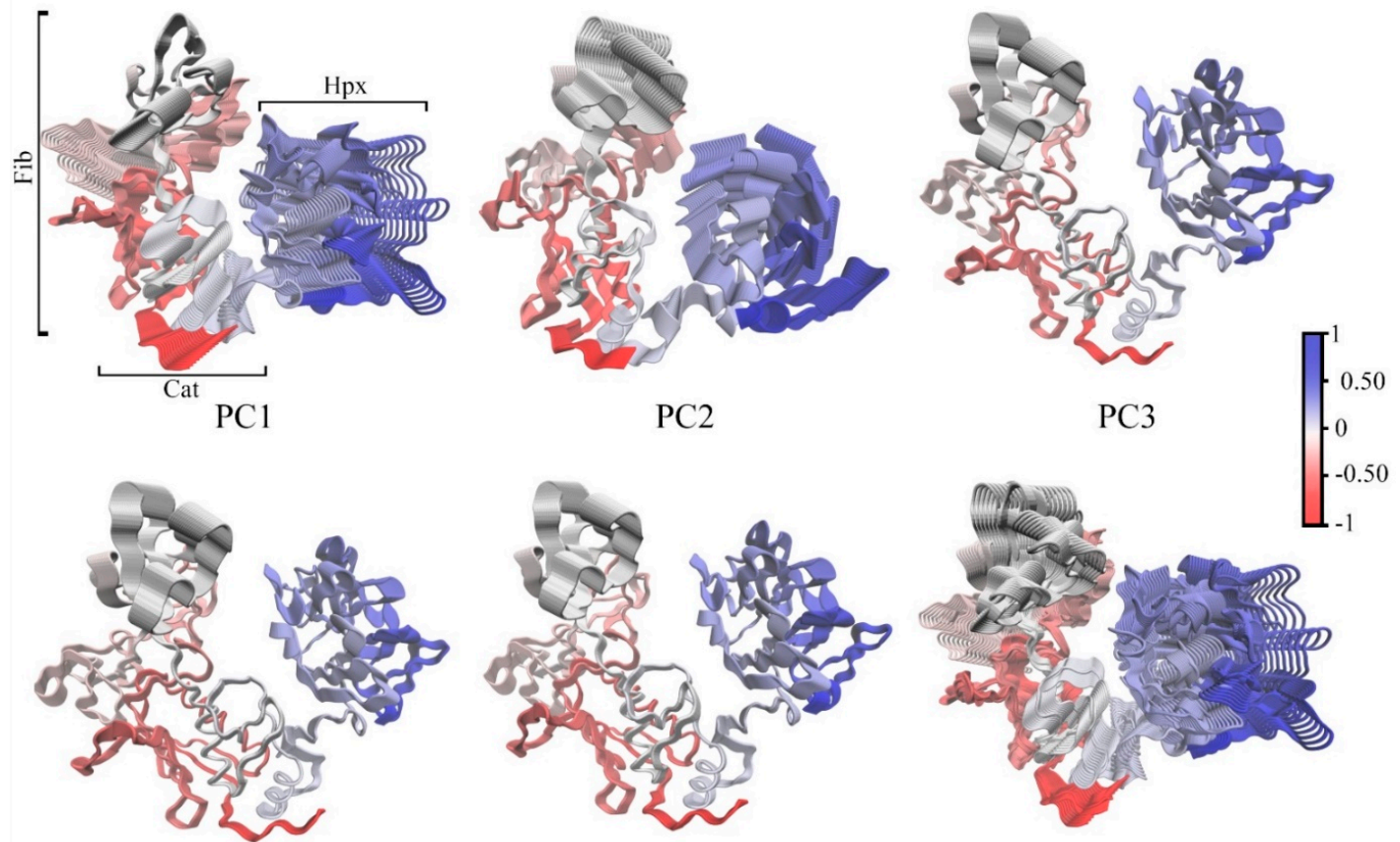

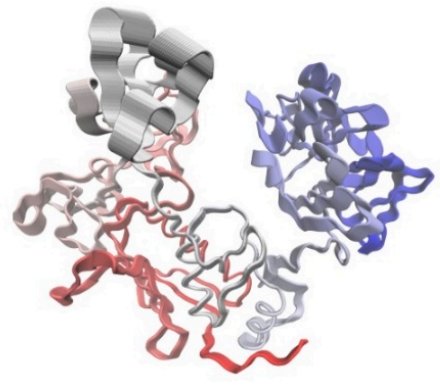

PC4

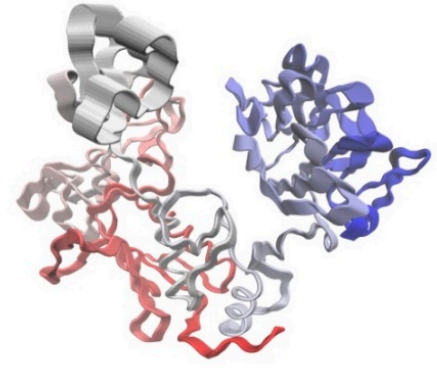

PC5

Figure 6. $\mathrm{C} \alpha$-trace of the first five principle components (PC1 through PC5) and an overlay of all principle components PC1-PC5. Correlated domain movements are indicated in blue and anti-correlated are in red.

\subsection{Protein-Metal Ion Interaction Energies}

MMP-2 has a high affinity for the bound divalent cations (Table 5) with a major contribution from the electrostatic interactions. The solvation term $\Delta G_{\text {polar }}$ is unfavorable particularly for the catalytic $\mathrm{Zn}^{2+}$ ion 1 , the structural $\mathrm{Ca}^{2+}$ ion 1 , and $\mathrm{Ca}^{2+}$ ion 3 and the $\Delta \mathrm{G}_{\text {non-polar }}$ is only weakly favorable. For the weakly bound $\mathrm{Zn}^{2+}$ ion 2 and the freely diffusing $\mathrm{Ca}^{2+}$ ion 2 , the $\Delta \mathrm{G}_{\text {polar }}$ is significantly smaller. The entropic contributions to MMP-2 divalent cation interaction energies are very small, but positive-indicating decreased system entropy with the binding of the metal ions to the peptide. The entropic term is lowest for those ions that for those metal ions $\left(\mathrm{Ca}^{2+}\right.$ ion 2 and $\mathrm{Ca}^{2+}$ ion 3$)$ that either diffuse freely away from their crystallographically determined binding sites or do not form close associations and stable binding geometries with the electronegative backbone and sidechain atoms of MMP-2 [32].

Table 5. Binding energies between MMP-2 and the associated divalent cations as determined by the MMPBSA-IE and interaction entropy methods with its associated components.

\begin{tabular}{|c|c|c|c|c|c|c|c|}
\hline \multicolumn{8}{|c|}{ Mean \pm Standard Deviation $/ \mathrm{kJ} \mathrm{mol}^{-1}$} \\
\hline Ion(s) & $\Delta \mathbf{E}_{\mathrm{vdw}}$ & $\Delta \mathrm{E}_{\text {elec }}$ & $\Delta \mathrm{G}_{\text {polar }}$ & $\Delta \mathrm{G}_{\text {non-polar }}$ & $-\mathrm{T} \Delta \mathrm{S}$ & $\Delta \mathrm{E}_{\text {binding }}$ & $\Delta \mathrm{G}_{\text {binding }}$ \\
\hline All ions & $95.04 \pm 2.92$ & $-9264.45 \pm 194.34$ & $3142.58 \pm 81.6$ & $-3.95 \pm 0.13$ & 6.77 & $-6020.73 \pm 116.75$ & $-6013.96 \pm 116.75$ \\
\hline $\mathrm{Zn}^{2+}$ ion 1 & $25.41 \pm 0.77$ & $-2427.66 \pm 72.19$ & $1291.3 \pm 42.75$ & $-0.88 \pm 0.04$ & 0.63 & $-1114.16 \pm 27.12$ & $-1113.51 \pm 27.12$ \\
\hline $\mathrm{Ca}^{2+}$ ion 1 & $38.15 \pm 1.90$ & $-1796.42 \pm 89.21$ & $605.84 \pm 30.55$ & $-1.14 \pm 0.07$ & 1.03 & $-1154.73 \pm 56.65$ & $-1153.69 \pm 56.65$ \\
\hline $\mathrm{Ca}^{2+}$ ion 2 & $6.52 \pm 0.58$ & $-367.21 \pm 36.96$ & $73.71 \pm 9.94$ & $-0.35 \pm 0.05$ & 0.18 & $-289.24 \pm 27.33$ & $-298.07 \pm 27.33$ \\
\hline $\mathrm{Ca}^{2+}$ ion 3 & $14.94 \pm 0.57$ & $-1480.59 \pm 42.61$ & $320.38 \pm 11.31$ & $-1.32 \pm 0.05$ & 0.23 & $-1147.96 \pm 30.78$ & $-1147.73 \pm 30.78$ \\
\hline
\end{tabular}

Residue contributions to the binding energy with their associated interatomic distances and geometries are given in Table 6, only those protein residues within the first coordination sphere of the divalent metal ion are noted with the exceptions of $\mathrm{Ca}^{2+}$ ion 2 and $\mathrm{Ca}^{2+}$ ion 3 which are discussed below $[17,18]$. The catalytic $\mathrm{Zn}^{2+}$ ion 1 maintains interactions with $\mathrm{His}^{403}, \mathrm{His}^{407}$, and $\mathrm{His}^{413}$, similar to what is observed in the $\mathrm{x}$-ray crystal structure. The $\mathrm{Glu}^{404}$ sidechain $\mathrm{O} \varepsilon$ atoms are in closer proximity 
than what is observed in the crystal structure; however, with distances that are consistent with prior simulations [30,31]. The binding geometry for the bound His residues is trigonal bipyramidal; however, if coordinated hydration water is considered, this geometry would be tetrahedral. Other important interactions are also noted between $\mathrm{Zn}^{2+}$ ion 1 and Asp and Glu residues within the Cat domain. These residues contribute significantly to the MMP-2- $\mathrm{Zn}^{2+}$ ion 1 interaction energy despite being outside what is considered to be the normal coordination sphere of the ion. This is not unexpected, given the strong long-distance coulombic interactions involved (Equation (2)). $\mathrm{Zn}^{2+}$ ion 2 loses contact with $\mathrm{His}^{178}$, $\mathrm{His}^{193}$, and $\mathrm{His}^{206}$ shifting to a more linear coordination geometry that is depended on a strong interaction with the $\mathrm{O} \delta$ atoms of $\mathrm{Asp}^{180}$. Comparison to prior simulation studies is not possible for the $\mathrm{Zn}^{2+}$ ions, since the parameters used represented the interactions between the divalent metal cation and the x-ray crystal structure associated residue sidechains as harmonic potentials [30]. This is an important point, since prior investigators have identified variations in the stoichiometry of the MMP-2- $\mathrm{Zn}^{2+}$ interaction that are strongly dependent on the purification procedure used possibly indicating that $\mathrm{Zn}^{2+}$ ion 2 may be able to dissociate from its binding site [33]. It should be noted that the current study assumes that all His residue sidechains are uncharged with a $\mathrm{pK}_{\mathrm{a}}=6.0$ at a system $\mathrm{pH}$ $=7.0$ [34]. This assumption cannot account for local environments that may cause the His sidechains to be protonated effecting $\mathrm{Zn}^{2+}$ binding as has been demonstrated for His residue interactions with other divalent cations and their metal binding site [35].

Table 6. Distances of ions to the interacting protein residue atoms identified from the 1CK7 X-ray crystal. Statistically significant protein residue atoms as identified by outlier analysis with the associated per residue interaction energies and binding geometry. $1 \mathrm{CK} 7$ identified interactions are marked with a dagger $(\dagger)$; statistically significant interactions are marked with an asterisk ${ }^{*}$ ); and binding geometries were determined for those atoms within $0.35 \mathrm{~nm}$. Distance is given in $\mathrm{nm}$ and energies in $\mathrm{kJ} \mathrm{mol}^{-1 \mathrm{a}, \mathrm{b}, \mathrm{c}}$.

\begin{tabular}{|c|c|c|c|c|c|c|c|}
\hline Protein Atom & $\Delta \mathrm{E}_{\text {binding }}$ & Geometry & $\mathrm{Zn}^{2+}$ Ion 1 & $\mathrm{Zn}^{2+}$ ion 2 & $\mathrm{Ca}^{2+}$ ion 1 & $\mathrm{Ca}^{2+}$ ion 2 & $\mathrm{Ca}^{2+}$ ion 3 \\
\hline $\mathrm{t}^{*} \mathrm{Glu}^{404}: \mathrm{O} \varepsilon 1$ & -154.8223 & & $0.46 \pm 0.05$ & & & & \\
\hline${ }^{*} \mathrm{Glu}^{404}: \mathrm{O} \varepsilon 2$ & & & $0.48 \pm 0.06$ & & & & \\
\hline${ }^{*} \mathrm{His}^{403}: \mathrm{N} \varepsilon 2$ & -72.1511 & trigonal pyramidal & $0.21 \pm 0.01$ & & & & \\
\hline${ }^{*} \mathrm{His}^{407}: \mathrm{N} \varepsilon 2$ & -66.3450 & trigonal pyramidal & $0.21 \pm 0.01$ & & & & \\
\hline${ }^{*} \mathrm{His}^{413}: \mathrm{N} \varepsilon 2$ & -61.5998 & trigonal pyramidal & $0.21 \pm 0.01$ & & & & \\
\hline †*Asp ${ }^{180}: \mathrm{O} 81$ & -92.3424 & linear & & $0.19 \pm 0.01$ & & & \\
\hline †*Asp $^{180}:$ O $\delta 2$ & & linear & & $0.19 \pm 0.01$ & & & \\
\hline †*Asp $^{185}:$ O $\delta 1$ & & seesaw & & & $0.29 \pm 0.16$ & & \\
\hline t*Asp $^{185}:$ O 82 & & seesaw & & & $0.28 \pm 0.16$ & & \\
\hline $\mathrm{t}^{*} \mathrm{Glu}^{211}: \mathrm{O} \varepsilon 1$ & -147.6924 & seesaw & & & $0.33 \pm 0.11$ & & \\
\hline †*Glu $^{211}: \mathrm{O} \varepsilon 2$ & & seesaw & & & $0.35 \pm 0.10$ & & \\
\hline$t^{*} \mathrm{Asp}^{208}: \mathrm{O} \delta 1$ & -142.7074 & seesaw & & & $0.34 \pm 0.09$ & & \\
\hline t*Asp $^{208}:$ O $\delta 2$ & & seesaw & & & $0.24 \pm 0.02$ & & \\
\hline${ }^{*} \mathrm{Asp}^{210}: \mathrm{O} \delta 1$ & -112.8532 & seesaw & & & $0.33 \pm 0.14$ & & \\
\hline${ }^{*} \mathrm{Asp}^{210}: \mathrm{O} \delta 2$ & & seesaw & & & $0.35 \pm 0.14$ & & \\
\hline Asp $^{168}: \mathrm{O} 81$ & & $\mathrm{~N} / \mathrm{C}$ & & & & $2.57 \pm 1.59$ & \\
\hline Asp $^{168}: 082$ & & $\mathrm{~N} / \mathrm{C}$ & & & & $2.54 \pm 1.60$ & \\
\hline +Ala ${ }^{167}: \mathrm{C}=\mathrm{O}$ & -1.3321 & $\mathrm{~N} / \mathrm{C}$ & & & & $2.52 \pm 1.75$ & \\
\hline tGly ${ }^{200}: C=O$ & 0.3799 & $\mathrm{~N} / \mathrm{C}$ & & & & $2.57 \pm 1.70$ & \\
\hline tGly ${ }^{202}: \mathrm{C}=\mathrm{O}$ & -1.0605 & $\mathrm{~N} / \mathrm{C}$ & & & & $2.55 \pm 1.56$ & \\
\hline${ }^{*} \mathrm{Asp}^{521}: \mathrm{O} \delta 2$ & & $\mathrm{~N} / \mathrm{C}$ & & & & & $0.98 \pm 0.16$ \\
\hline$\dagger^{*} \operatorname{Asp}^{569}: \mathrm{C}=\mathrm{O}$ & -79.0260 & $\mathrm{~N} / \mathrm{C}$ & & & & & $0.71 \pm 0.18$ \\
\hline${ }^{*} \mathrm{Asp}^{569}$ :O 81 & & $\mathrm{~N} / \mathrm{C}$ & & & & & $0.92 \pm 0.15$ \\
\hline${ }^{*} \mathrm{Asp}^{569}: \mathrm{O} \delta 2$ & & $\mathrm{~N} / \mathrm{C}$ & & & & & $0.91 \pm 0.15$ \\
\hline${ }^{*} \mathrm{Asp}^{490}: \mathrm{O} \delta 1$ & -69.0106 & $\mathrm{~N} / \mathrm{C}$ & & & & & $1.19 \pm 0.11$ \\
\hline${ }^{*} \mathrm{Asp}^{490}: \mathrm{O} 82$ & & $\mathrm{~N} / \mathrm{C}$ & & & & & $1.19 \pm 0.11$ \\
\hline${ }^{*} \mathrm{Asp}^{615}: \mathrm{O} 81$ & -68.1150 & $\mathrm{~N} / \mathrm{C}$ & & & & & $1.29 \pm 0.14$ \\
\hline${ }^{*} \mathrm{Asp}^{615}: \mathrm{O} 82$ & & $\mathrm{~N} / \mathrm{C}$ & & & & & $1.30 \pm 0.14$ \\
\hline${ }^{*} \mathrm{Asp}^{153}: \mathrm{O} 81$ & -63.3125 & $\mathrm{~N} / \mathrm{C}$ & & & & & $2.52 \pm 0.96$ \\
\hline${ }^{*}{ }^{*} p^{153}: O 82$ & & $\mathrm{~N} / \mathrm{C}$ & & & & & $2.51 \pm 0.95$ \\
\hline${ }^{*} \mathrm{Asp}^{472}: \mathrm{O} 81$ & -54.3377 & $\mathrm{~N} / \mathrm{C}$ & & & & & $1.54 \pm 0.15$ \\
\hline${ }^{*} \mathrm{Asp}^{472}: \mathrm{O} 82$ & & $\mathrm{~N} / \mathrm{C}$ & & & & & $1.54 \pm 0.15$ \\
\hline
\end{tabular}


$\mathrm{Ca}^{2+}$ ion 1 has strong interactions with the adjacent $\mathrm{O} \delta$ atoms of Asp and $\mathrm{O} \varepsilon$ atoms of Glu of adjacent residues. There is a shift from the divalent cation to backbone carbonyl oxygen interactions that are observed in the crystal structure to interactions dominated by the acidic sidechain groups. The coordination geometry changes from pentagonal pyramidal to a square planar geometry. The strong interactions and coordination with these sidechains is expected and has been previously observed for other systems [36]. The results for $\mathrm{Ca}^{2+}$ ion 1 are the same as noted in prior simulations with a shift from backbone carbonyl interactions, which may represent crystal packing forces to interactions with the carboxyl sidechains [30]. In general, the favorability of the interaction is Glu>Asp, with the difference attributed to the increased flexibility of the Glu residue, secondary to the presence of the extra methylene group. The binding of this ion is also similar to that of the catalytic $\mathrm{Zn}^{2+}$ ion 1 in that adjacent, but non-coordinated electronegative Asp and Glu residues make significant contributions to its binding energy secondary to the strong long range coulomb interactions. $\mathrm{Ca}^{2+}$ ion 2 and $\mathrm{Ca}^{2+}$ ion 3 represent special cases. $\mathrm{Ca}^{2+}$ ion 2 freely diffuses out of its binding site, and any strong interactions with electrostatic sidechains are transient. The $\mathrm{x}$-ray crystal structure associated atoms are given to illustrate this, Although prior simulations do note the $\mathrm{Ca}^{2+}$ ion 2 leaving its binding site, they do note that the associated interactions are weak and the study is most likely limited by the short simulation time (10 ns) [30]. $\mathrm{Ca}^{2+}$ ion 3 is more stable in its RMSF compared to $\mathrm{Ca}^{2+}$ ion 2 (Table 3); however, it is still much more variable than the other associated ions. This ion breaks its association with the backbone carbonyl atoms of Asp ${ }^{476}$, Asp ${ }^{521}$, Asp ${ }^{569}$ and $\mathrm{Asp}^{618}$ to form strong interactions with multiple Asp carboxyl oxygens as given in Table 6. This result is most likely due to the change from crystal packing forces to that of an aqueous environment [36].

\section{Materials and Methods}

\subsection{Matrix Metalloprotease-2 Starting Conformation}

Initial coordinates were obtained from the X-ray crystal structure of the $\mathrm{Glu}^{404}$ to $\mathrm{Ala}^{404}$ mutant of the human MMP-2 (PDB ID: 1CK7) [13]. Crystallographically resolved water and sulfate ions were removed while the protein bound $\mathrm{Zn}^{2+}, \mathrm{Ca}^{2+}, \mathrm{Na}^{+}$, and $\mathrm{Cl}^{-}$ions where retained. Residues 31-109 were removed as in the biologically active form of the enzyme. The crystallography non-resolved loop from residues Asp ${ }^{450}-\mathrm{Thr}^{460}$ was build using the homology modelling script of YASARA [16]. The coordinates for the sidechain of $\mathrm{Glu}^{404}$ and the $\mathrm{Zn}^{2+}$ coordinated water molecule that replaces $\mathrm{Cys}^{102}$ at the enzyme active site were derived from the MMP-13 crystal structure (PDB ID: 1XUD) by the least squares fitting of the backbone and $\mathrm{Zn}^{2+}$ atoms of both $\mathrm{x}$-ray structures [37]. Sidechain protonation states of the $\mathrm{Zn}^{2+}$ associated His residues were assigned based on the $1 \mathrm{CK} 7$ crystal structure as follows: HND1 for His ${ }^{178}, \mathrm{His}^{403}$, $\mathrm{His}^{193}$, $\mathrm{His}^{407}, \mathrm{His}^{413}$, and HNE2 for His ${ }^{206}$. The remaining Histidine residues ( $\mathrm{His}^{163}{ }^{16} \mathrm{His}^{276}$, and $\mathrm{His}^{628}$ ) were assigned automatically with HNE2 atoms using the $p d b 2 g m x$ module of GROMACS version 5.1.2 [38,39]. The protonation state and charges of all other residues within the protein were set to correspond to a $\mathrm{pH}$ of 7.0 with the His residues sidechains assigned in their uncharged state consistent with NMR titration studies [34].

\subsection{Molecular Dynamics}

Simulations were performed using the CHARMM36m force field with modified TIP3Pm water model and the CM model of divalent metal cation parameters of $\mathrm{Li}$ et al. as implemented in GROMACS version 5.1.2 $\left[\mathrm{Zn}^{2+}\left(\sigma=0.226466454151 \mathrm{~nm}, \varepsilon=0.01381916624 \mathrm{~kJ} \mathrm{~mol}^{-1}\right)\right.$ and $\mathrm{Ca}^{2+}$ $\left(\sigma=0.293818397243 \mathrm{~nm}, \varepsilon=0.44320568080 \mathrm{~kJ} \mathrm{~mol}^{-1}\right)$ ] [40-45]. The CM model attempts to balance hydration free energy by optimizing the ion-oxygen distance in the first solvation shell. The metal ions are represented with a standard Lennard-Jones and coulomb potential energy functions [46]:

$$
E_{i o n}=\sum_{j}^{N} 4 \varepsilon_{i j}\left[\left(\frac{\sigma_{i j}}{r_{i j}}\right)^{12}-\left(\frac{\sigma_{i j}}{r_{i j}}\right)^{6}\right]+\sum_{j}^{N} \frac{q_{i} q_{j}}{4 \pi \varepsilon_{0} r_{i j}},
$$


where, $\sigma_{\mathrm{ij}}$, is the distance between two atoms at their lowest potential energy calculated as an arithmetic mean,

$$
\sigma_{i j}=\frac{\left(\sigma_{i}+\sigma_{j}\right)}{2}
$$

$\varepsilon_{\mathrm{ij}}$, is the depth of the potential energy well calculated as a geometric mean,

$$
\varepsilon_{i j}=\sqrt[2]{\left(\varepsilon_{i} \bullet \varepsilon_{j}\right)}
$$

$\mathrm{q}_{\mathrm{i}}$ and $\mathrm{q}_{\mathrm{j}}$ are the respective point charges, $\mathrm{r}_{\mathrm{ij}}$ is the distance separating the two atoms, $\varepsilon_{0}$ is the dielectric constant, and $i$ and $j$ are atom indices. The system was solvated in a truncated dodecahedron with 45105 TIP3Pm water molecules. The minimal distance of the protein to the edge of the dodecahedron was $1.4 \mathrm{~nm}$. The system was neutralized with 141 and 132, $\mathrm{Na}^{+}$and $\mathrm{Cl}^{-}$ions, respectively, so that the final concentration of the $\mathrm{NaCl}$ was set to $150 \mathrm{mM}$; the initially retained protein bound $\mathrm{Zn}^{2+}$, $\mathrm{Ca}^{2+}, \mathrm{Na}^{+}$, and $\mathrm{Cl}^{-}$ions are not included. The size of the box was $1458.26 \mathrm{~nm}^{3}$, containing 8487 protein and divalent metal cation atoms and 45106 water molecules giving an MMP-2 concentration of $1.1 \mathrm{mM}$, a $\mathrm{Zn}^{2+}$ concentration of $2.2 \mathrm{mM}$ and a $\mathrm{Ca}^{2+}$ concentration of $3.3 \mathrm{mM}$. The mean \pm standard deviation concentrations of non-protein bound $\mathrm{Zn}^{2+}$ and $\mathrm{Ca}^{2+}$ in the plasma of healthy human adults are $81 \pm 16 \mathrm{nM}$ and $1.19 \pm 0.06 \mathrm{mM}$, respectively [47,48]. The system was subjected to 5000 steps of steepest descent energy minimization, allowing all bond distances and angles to relax. This was followed with $10 \mathrm{~ns}$ of NVT simulation at $310 \mathrm{~K}$ so that the position of the protein heavy atoms and retained $\mathrm{Zn}^{2+}, \mathrm{Ca}^{2+}, \mathrm{Na}^{+}$, and $\mathrm{Cl}^{-}$ions and catalytic $\mathrm{Zn}^{2+}$ associated water were constrained to their energy-minimized coordinates with force constant of $1000 \mathrm{~kJ} \mathrm{~mol}^{-1}$. The solvent and non-restrained $\mathrm{Na}^{+}$and $\mathrm{Cl}^{-}$ions were then subjected to $10 \mathrm{~ns}$ of NPT simulation at $310 \mathrm{~K}$ and $101.325 \mathrm{kPa}$ using Berendsen temperature and pressure scaling with a relaxation constant of $0.1 \mathrm{ps}$ and $4.5 \times 10^{-5} \mathrm{bar}^{-1}$ isothermal compressibility [49]. The heavy atom restraints were removed and the system subjected to $10 \mathrm{~ns}$ of NPT dynamics ( $310 \mathrm{~K}$ and $101.325 \mathrm{kPa}$ ). Velocities were assigned and rescaled stochastically and the pressure coupled with the Berendsen method (relaxation constant, 0.1 ps and isothermal compressibility, $4.5 \times 10^{-5} \mathrm{bar}^{-1}$ ) [50]. The production run consisted of $1.0 \mu$ s NPT simulation $(310 \mathrm{~K}$ and $101.325 \mathrm{kPa}$ ). Trajectories were integrated with a $2 \mathrm{fs}$ time step. All bonds were constrained to their correct length using LINCS, with a warning angle of $30^{\circ}[51,52]$. The long-range electrostatic interactions were calculated using the PME method with $1.2 \mathrm{~nm}$ cutoff distance and $0.15 \mathrm{~nm}$ Fourier spacing [53]. Van der Waals interactions were calculated using short-range and long-range cutoffs of 1.0 and $1.2 \mathrm{~nm}$ respectively with a linear smoothing function. The temperature was maintained by the stochastic velocity-rescaling method, and the system was coupled to a Parrinello-Rahman barostat $[50,54]$.

\subsection{Biophysical Properties}

The $\mathrm{C} \alpha$-trace root mean square deviation (RMSD) and per-residue root mean square fluctuation (RMSF) from the average sampled peptide conformation were calculated with the $g_{-} r m s d$ and $g_{-} r m s f$ utilities of GROMACS, respectively [39]. The $>50 \%$ of the simulation time sampled per-residue DSSP assigned [24] secondary structure ( $\alpha$-helix, $\beta$-sheet, $\beta$-bend/turn, and coil) were determined using the do_dssp utility of GROMACS and an in house perl script to calculate sampling statistics. The hydration of the $\mathrm{Zn}^{2+}$ and $\mathrm{Ca}^{2+}$ was determined by calculating the radial distribution function for the oxygen atom of the surrounding water molecules using the g_rdf utility in GROMACS [39]. The distances from the ion to the first and second hydration shells is determined by examining the peaks and troughs of the associated RDF. The integral of the RDF $(g(r))$ :

$$
\rho_{r}=\int_{0}^{r} \mathrm{~g}(\mathrm{r}) \mathrm{dr}
$$


is the statistical density of the surrounding solvent and represents the probability of a solvent molecule being located within $r$ distance of the central atom or group at any sampled time. At an infinite distance this probability is by definition 1.0. The coordination number $(\mathrm{CN})$ can then be calculated as:

$$
C N=4 \cdot \pi \cdot \rho \int_{0}^{r} g(r) r^{2} d r
$$

where $\rho$ is the density and $r$ the distance from the ion $[55,56]$.

\subsection{Conformational Analysis}

The time-dependent $\phi / \psi$ dihedral angles from residues 111 to 659 were calculated using the g_rama utility of GROMACS and transformed into appropriate input files using a python script. The dihedral principle component analysis (dPCA) program was provided by Dr. Yuguang Mu $[57,58]$. Lowest energy conformations were identified by projecting the trajectories of the first two principal components ( $\mathrm{dPC} 1$ and $\mathrm{dPC} 2)$ onto a two-dimensional free energy $(\Delta \mathrm{G})$ landscape:

$$
\Delta G=-R \cdot T \cdot \ln \frac{\rho_{x, y}}{\rho_{\max }}
$$

where $\mathrm{R}$ is the universal gas constant, $\mathrm{T}$ is the temperature, $\mathrm{x}$ and $\mathrm{y}$ are the first two dihedral principal components from the trajectory. The free energy $(\Delta \mathrm{G})$ landscape was calculated by dividing the $\mathrm{dPC} 1-\mathrm{dPC} 2$ subspace into grids creating a 2D histogram of the sampled phase space and calculating the probability $\rho_{x, y}$ where $\rho_{\max }$ is the grid value corresponding to the maximum probability of occurrence. The free energy landscape was visualized using the scatterplot3D, akima, and latticeExtra packages in the $\mathrm{R}$ [59-61]. K-means clustering (cluster package in R) was used to identify families of conformations and the lowest energy conformations extracted for analysis [22,23]. The optimal clustering was determined using a combination of visual inspection, sum of squared error (SSE), average silhouette width ( $\left.\mathrm{S}_{\mathrm{AVG}}\right)$, silhouette coefficient (SC) and distribution plots [62-65]. Conformations and secondary structural elements were rendered using YASARA [16].

\subsection{Dynamic Cross-Correlation Matrix}

Domains movement and correlations were evaluated by dynamic cross-correlation matrices (DCCM) calculated from the $\mathrm{C} \alpha$-trace covariance matrix principal components using the GeoStaS method (Bio3D package in R) [66-68]. Results are displayed as a color coded matrix of Pearson correlation coefficients with a value of -1 indicated completely anti-correlated motions and a value of +1 indicating completely correlated motions [69,70].

\subsection{Interaction Energy}

The free energy of binding between the metal cations and protein was calculated using the g_mmpbsa program [71]. The polar component of the solvation energy was calculated using the Poisson-Boltzmann equation and non-polar component calculated from the solvent-accessible surface area approximation [72,73]. Dielectric constants for the solute and water were 4 and 80 , respectively. The entropic contribution to the binding energy was determined using the interaction entropy method of Zhang and coworkers [32,74]. The method defines the entropic contribution to the free energy term as:

$$
-T \Delta S=R \cdot T \cdot \ln \left\langle e^{\beta \Delta E_{p l}^{i n t}}\right\rangle
$$

where $\mathrm{R}$ is the universal gas constant, $\mathrm{T}$ the temperature, $\beta$ is the thermodynamics beta:

$$
\beta=\frac{1}{k_{B} T},
$$


$\beta$ is Boltzmann's constant, $\mathrm{T}$ is temperature, and $\Delta \mathrm{E}_{\mathrm{pl}}{ }^{\text {int }}$ is defined as:

$$
\Delta E_{p l}^{i n t}=E_{p l}^{i n t}-\left\langle E_{p l}^{i n t}\right\rangle
$$

$\left\langle E_{p l}^{i n t}\right\rangle$ is the ensemble averaged protein-ligand interaction energy, and $E_{\mathrm{pl}}{ }^{\text {int }}$ is the protein-ligand interaction energy for a sampled conformation. For molecular dynamics simulations containing $\mathrm{N}$ sampled conformations, the interaction entropy can then be calculated as:

$$
\left\langle\mathrm{e}^{\beta \Delta \mathrm{E}_{\mathrm{pl}}^{\mathrm{int}}}\right\rangle=\frac{1}{\mathrm{~N}} \sum \mathrm{e}^{\beta \Delta \mathrm{E}_{\mathrm{pl}}^{\mathrm{int}}}
$$

The trajectory was sampled every $0.1 \mathrm{~ns}$ for the equilibrium phase ( $200 \mathrm{~ns}$ to $1000 \mathrm{~ns}$ ). A bootstrap analysis $(n=5000)$ was performed to obtain standard errors, and the residue contributions to the binding energy were also calculated.

The residue contributions to binding were deconvoluted. To determine the most significant residue interactions between MMP-2 and the divalent cations, an outlier analysis was performed to identify statistically significant interactions. The distribution of interaction energies was not Gaussian (normal). In the setting of non-normal distributions, the method of Tukey's fences can be used to identify those observations that are outside of the expected fluctuations within the data [75]. Tukey's fences defines the minimum and maximum values of the interaction energy:

$$
\text { [MinimumValue, MaximumValue], }
$$

such that measurements less than or equal to the minimum value or greater than or equal to the maximum value are considered statistical outliers. The respective minimum and maximum values of the fences, are defined as:

$$
\left[Q_{1}-k\left(Q_{3}-Q_{1}\right), Q_{3}+k\left(Q_{3}-Q_{1}\right)\right],
$$

where $Q_{1}, Q_{3}$ are the interquartile values, and $k$ is the constant that defines the outlier range $(k=1.5$ is an outlier, $\mathrm{k}=3.0$ is an extreme outlier) [75].

\section{Conclusions}

We report a microsecond scale molecular dynamics analysis of the full biologically active protein (Cat, Fib, and Hpx domains with Lnk region) with its crystallographically associated (structural) divalent metal ions $\left(\mathrm{Zn}^{2+}\right.$ and $\left.\mathrm{Ca}^{2+}\right)$. Our model indicates that MMP-2 undergoes significant inter domain motions. The $\mathrm{R}_{\mathrm{g}}$ and $\mathrm{COM}$ data demonstrate five macro distributions of conformations based on size. The dPCA data is consistent with ten families of conformations. The three lowest energy populations of conformations differ predominantly in the orientation of the Hpx domain in relation to the Cat and Fib domains. This is confirmed by the DCCM analysis, where the difference in orientation of the Hpx to the Cat and Fib domains comprises the first two principle components. These inter domain movements are facilitated by the flexible linker region Gly ${ }^{446}$ through Asp ${ }^{476}$ and may play an important role in collagen substrate binding, unravelling and subsequent catalysis.

$\mathrm{Zn}^{2+}$ ion 1 (catalytic ion) and $\mathrm{Ca}^{2+}$ ion 1 are tightly bound within their crystallographically defined pockets. $\mathrm{Zn}^{2+}$ ion 2 was more flexible and associated with the S-loop which has demonstrated increased flexibility in both prior simulations and our own; however, the use of short simulation time (10 ns) and a harmonic potential representing the interaction between the $\mathrm{Zn}^{2+}$ ion and the associated His and Asp/Glu residues may have artificially stabilized the protein- $\mathrm{Zn}^{2+}$ ion 2 interaction. $\mathrm{Ca}^{2+}$ ion 2 and $\mathrm{Ca}^{2+}$ ion 3 do not remain in their crystallographically defined positions. Although $\mathrm{Ca}^{2+}$ ion 3 is more closely associated with the Hpx domain, the carboxyl sidechains of the Asp residues that contribute to its interaction are at distances well outside of the coordination sphere. 
The current non-bonded model of Li et al. with the CHARMM36m force field appears to be a reasonable model of protein metal cation interactions in MMP-2 [45]. The data suggest that further models should retain $\mathrm{Zn}^{2+}$ ion $1, \mathrm{Zn}^{2+}$ ion 2 and $\mathrm{Ca}^{2+}$ ion 1 , since they play important chemical and conformational roles and remove $\mathrm{Ca}^{2+}$ ion 2 and possibly $\mathrm{Ca}^{2+}$ ion 3 , since their role is minimal. Protein-ligand binding studies should also include multiple conformations to account for the mobility of the Hpx domain with respect to the Cat and Fib domains. We do, however, acknowledge that the Li et al. with the CHARMM36m force field has known limitations. Accurate protein-metal ion interaction energies and coordination geometries require either the use of a carefully parameterized polarizable force field or more computationally expensive QM/MM simulations.

Supplementary Materials: Supplementary materials can be found at http://www.mdpi.com/1422-0067/20/17/ 4194/s1.

Author Contributions: Conceptualization, C.R.W and S.L.; methodology, C.R.W and S.L.; software, C.R.W., L.V.-O., and S.L.; validation, C.R.W. and L.V.-O.; formal analysis, C.R.W. and L.V.-O.; investigation, L.V.-O.; resources, C.R.W.; data curation, L.V.-O.; writing—original draft preparation, C.R.W.; writing—review and editing, C.R.W, L.V.-O., and S.L.; visualization, L.V.-O.; supervision, C.R.W. and S.L.; project administration, C.R.W.; funding acquisition, C.R.W.

Funding: Funding for this investigation was provided in part through a grant from Mayo Clinic Health System-Franciscan Healthcare Foundation Inc. and Mayo Foundation for Medical Education and Research.

Acknowledgments: The molecular dynamics simulations and subsequent analysis were completed using the High Performance Cluster, Resource Computing Services, Mayo Clinic, Rochester, Minnesota.

Conflicts of Interest: Charles R. Watts is a consultant for Medtronic Spine and Biologics. The remaining authors have disclosed that they do not have any conflicts of interest. The funders had no role in the design of the study; in the collection, analyses, or interpretation of data; in the writing of the manuscript, or in the decision to publish the results.

\section{Abbreviations}

$\begin{array}{ll}\text { CN } & \text { Coordination number } \\ \text { dPCA } & \text { Dihedral principle component analysis } \\ \text { DCCM } & \text { Domain cross-correlation matrix } \\ \text { DSSP } & \begin{array}{l}\text { Database of secondary structure assignments for all protein entries in } \\ \text { the Protein Data Bank }\end{array} \\ \text { MD } & \text { Molecular dynamics } \\ \text { MMP-2 } & \text { Matrix metalloproteinase-2 } \\ \text { MMPBSA-IE } & \text { Molecular mechanics Poisson Boltzman surface area - interaction } \\ & \text { entropy } \\ \text { NVT } & \text { Constant number, volume, and temperature } \\ \text { NPT } & \text { Constant number, pressure, and temperature } \\ \text { PDB } & \text { Protein databank } \\ \text { PME } & \text { Particle mesh Ewald } \\ \text { RMSD } & \text { Root mean square deviation } \\ \text { RMSF } & \text { Root mean square fluctuation } \\ \text { SASA } & \text { Solvent exposed surface area }\end{array}$

\section{References}

1. Basbaum, C.B.; Werb, Z. Focalized proteolysis: Spatial and temporal regulation of extracellular matrix degradation at the cell surface. Curr. Opin. Cell Biol. 1996, 8, 731-738. [CrossRef]

2. Birkedal-Hansen, H.; Moore, W.G.; Bodden, M.K.; Windsor, L.J.; Birkedal-Hansen, B.; DeCarlo, A.; Engler, J.A. Matrix metalloproteinases: A review. Crit. Rev. Oral Biol. Med. 1993, 4, 197-250. [CrossRef]

3. Maskos, K. Crystal structure of MMPs in complex with physiological and pharmacological inhibitors. Biochimie 2005, 87, 249-263. [CrossRef] [PubMed]

4. Ra, H.-J.; Parks, W.C. Control of Matrix Metalloproteinase Catalytic Activity. Matrix Biol. 2007, 26, 587-596. [CrossRef] [PubMed] 
5. Verma, R.P.; Hansch, C. Matrix metalloproteinases (MMPs): Chemical-biological functions and (Q) SARs. Bioorg. Med. Chem. 2007, 15, 2223-2268. [CrossRef] [PubMed]

6. van Meurs, J.; van Lent, P.; Holthuysen, A.; Lambrou, D.; Bayne, E.; Singer, I.; van den Berg, W. Active matrix metalloproteinases are present in cartilage during immune complex mediated arthritis: A pivotal role for stromelysin-1 in cartilage destruction. J. Immunol. 1999, 163, 5633-5639.

7. Nagase, H.; Woessner, J.F., Jr. Matrix metalloproteinases. J. Biol. Chem. 1999, 274, 21491-21494. [CrossRef]

8. Steffensen, B.; Häkkinen, L.; Larjava, H. Proteolytic events of wound-healing-coordinated interactions among matrix metalloproteinases (MMPs), integrins, and extracellular matrix molecules. Crit. Rev. Oral Biol. Med. 2001, 12, 373-398. [CrossRef]

9. Egeblad, M.; Werb, Z. New functions for the matrix metalloproteinases in cancer progression. Nat. Rev. Cancer 2002, 2, 163-176. [CrossRef]

10. Fingleton, B. Matrix metalloproteinases: Roles in cancer and metastasis. Front. Biosci. 2006, 11, 479-491. [CrossRef]

11. Butler, G.S.; Overall, C.M. Updated biological roles for matrix metalloproteinases and new "intracellular" substrates revealed by degradomics. Biochemistry 2009, 48, 10830-10845. [CrossRef]

12. Rodríguez, D.; Morrison, C.J.; Overall, C.M. Matrix metalloproteinases: What do they not do? New substrates and biological roles identified by murine models and proteomics. Biochim. Biophys. Acta 2010, 1803, 39-54. [CrossRef] [PubMed]

13. Morgunov, E.; Tuuttila, A.; Bergmann, U.; Isupov, M.; Lindqvist, Y.; Schneider, G.; Tryggvason, K. Structure of Human Pro-Matrix Metalloproteinase-2: Activation Mechanism Revealed. Science 1999, 284, 1667-1670. [CrossRef]

14. Díaz, N.; Suárez, D.; Valdés, H. From the X-ray Compact Structure to the Elongated form of the Full-Length MMP-2 Enzyme in Solution: A Molecular Dynamics Study. J. Am. Chem. Soc. 2008, 130, 14070-14071. [CrossRef]

15. Díaz, N.; Suárez, D. Alternative Interdomain Configurations of the Full-Length MMP-2 Enzyme Explored by Molecular Dynamics Simulations. J. Phys. Chem. B 2012, 116, 2677-2686. [CrossRef]

16. Krieger, E.; Vriend, G. YASARA View-Molecular graphics for all devices—From smartphones to workstations. Bioinformatics 2011, 30, 2981-2982. [CrossRef]

17. Zheng, H.; Chruszcz, M.; Lasota, P.; Lebioda, L.; Minor, M. Data mining of metal ion environments present in protein structures. J. Inorg. Biochem. 2008, 102, 1765-1776. [CrossRef]

18. Zheng, H.; Cooper, D.R.; Porebski, P.J.; Shabalin, I.G.; Handing, K.B.; Minor, W. CheckMyMetal: A macromolecular metal-binding validation tool. Acta Cryst. 2017, 73, 223-233. [CrossRef] [PubMed]

19. Amadei, A.; Ceruso, M.A.; Di Nola, A. On the convergence of the conformational coordinates basis set obtained by the essential dynamics analysis of proteins' molecular dynamics simulations. Proteins 1999, 36, 419-424. [CrossRef]

20. Hayward, S.; de Groot, B.L. Normal modes and essential dynamics. In Methods in Molecular Biology: Molecular Modeling of Proteins; Kukol, A., Ed.; Humana Press: New York, NY, USA, 2008; Volume 443, pp. 89-106. ISBN 978-1-59745-177-2.

21. Andricioaei, I.; Karplus, M. On the calculation of entropy from covariance matrices of the atomic fluctuations. J. Chem. Phys. 2001, 115, 6289-6292. [CrossRef]

22. R Core Team. R: A Language and Environment for Statistical Computing. Available online: http: //www.R-project.org/ (accessed on 2 January 2019).

23. Maechler, M.; Rousseeuw, P.; Struyf, A.; Hubert, M.; Hornik, K.; Studer, M.; Roudier, P.; Gonzalez, J.; Kozlowski, K. Cluster: Methods for Cluster Analysis. Available online: https://cran.r-project.org/web/ packages/cluster/ (accessed on 2 January 2019).

24. Kabsch, W.; Sander, C. Dictionary of protein secondary structure: Pattern recognition of hydrogen-bonded and geometrical features. Biopolymers 1983, 22, 2577-2637. [CrossRef] [PubMed]

25. Steffensen, B.; Wallon, U.M.; Overall, C.M. Extracellular matrix binding properties of recombinant fibronectin type II-like modules of human 72-kDa gelatinase/type IV collagenase. High affinity binding to native type I collagen but not native type IV collagen. J. Biol. Chem. 1995, 270, 11555-11566. [CrossRef]

26. Gehrmann, M.L.; Douglas, J.T.; Bányai, L.; Hedvig, T.; Patthy, L.; Llinás, M. Modular autonomy, ligand specificity, and functional cooperativity of the three in-tandem fibronectin type II repeats from human matrix metalloproteinase 2. J. Biol. Chem. 2004, 279, 46921-46929. [CrossRef] [PubMed] 
27. Xu, X.; Wang, Y.; Lauer-Fields, J.L.; Fields, G.B.; Steffensen, B. Contributions of the MMP-2 collagen binding domain to gelatin cleavage. Substrate binding via the collagen binding domain is required for hydrolysis of gelatin but not short peptides. Matrix Biol. 2004, 23, 171-181. [CrossRef] [PubMed]

28. Xu, X.; Mikhailova, M.; Llangovan, U.; Chen, Z.; Yu, A.; Pal, S.; Hinck, A.P.; Steffensen, B. Nuclear magnetic resonance mapping and functional confirmation of the collagen binding sites of matrix metalloproteinase- 2 . Biochemistry 2009, 48, 5822-5831. [CrossRef] [PubMed]

29. Díaz, N.; Suárez, D. Molecular dynamics simulations of the active matrix metalloproteinase-2: Positioning of the N-terminal fragment and binding of a small peptide substrate. Proteins 2008, 72, 50-61. [CrossRef]

30. Díaz, N.; Suárez, D. Molecular Dynamics Simulations of Matrix Metalloproteinase 2: Role of the Structural Metal Ions. Biochemistry 2007, 46, 8943-8952. [CrossRef]

31. Díaz, N.; Suárez, D. Peptide Hydrolysis Catalyzed by Matrix Metalloproteinase 2: A computational Study. J. Phys. Chem. B 2008, 112, 8412-8424. [CrossRef]

32. Duan, L.; Liu, X.; Zhang, J.Z.H. Interaction Entropy: A New Paradigm for Highly Efficient and Reliable Computation of Protein-Ligand Binding Free Energy. J. Am. Chem. Soc. 2016, 138, 5722-5728. [CrossRef]

33. Springman, E.B.; Nagase, H.; Birkedal-Hansen, H.; Van Wart, H.E. Zinc content and function in human fibroblast collagenase. Biochemistry 1995, 34, 15713-15720. [CrossRef]

34. Li, S.; Hong, M. Protonation, Tautomerization, and Rotameric Structure of Histidine: A comprehensive Study by Magic-Angle-Spinning Solid-State NMR. J. Am. Chem. Soc. 2011, 133, 1534-1544. [CrossRef]

35. Langella, E.; Improta, R.; Barone, V. Checking the $\mathrm{pH}$-Induced Conformational Transition of Prion Protein by Molecular Dynamics Simulations: Effect of Protonation of Histidine Residues. Biophys. J. 2004, 87, 3623-3632. [CrossRef]

36. Cates, M.S.; Teodoro, M.L.; Phillips, G.N., Jr. Molecular Mechanisms of Calcium and Magnesium Binding to Parvalbumin. Biophys. J. 2002, 82, 1133-1146. [CrossRef]

37. Engel, C.K.; Pirard, B.; Schimanski, S.; Kirsch, R.; Habermann, J.; Klingler, O.; Schlotte, V.; Weithmann, K.U.; Wendt, K.U. Structural basis for the highly selective inhibition of MMP-13. Chem. Biol. 2005, 12, 181-189. [CrossRef]

38. Abraham, M.J.; Murtola, T.; Schulz, R.; Páll, S.; Smith, J.C.; Hess, B.; Lindahl, E. GROMACS: High performance molecular simulations through multi-level parallelism from laptops to supercomputers. SoftwareX 2015, 1-2, 19-25. [CrossRef]

39. Abraham, M.J.; van der Spoel, D.; Lindahl, E.; Hess, B.; the GROMACS Development Team. GROMACS User Manual ver. 5.1.2 2016. Available online: http://www.gromacs.org (accessed on 2 January 2019).

40. Huang, J.; Rauscher, S.; Nawrocki, G.; Ran, T.; Feig, M.; de Groot, B.L.; Grubmüller, H.; MacKerell, A.D., Jr. CHARMM36m: An improved force field for folded and intrinsically disordered proteins. Nat. Methods 2017, 14, 71-73. [CrossRef]

41. Best, R.B.; Zhu, X.; Shim, J.; Lopes, P.E.; Mittal, J.; Feig, M.; Mackerell, A.D., Jr. Optimization of the Additive CHARMM All-Atom Protein Force Field Targeting Improved Sampling of the Backbone $\phi, \psi$ and Side-Chain $\chi^{1}$ and $\chi^{2}$ Dihedral Angles. J. Chem. Theory Comput. 2012, 8, 3257-3273. [CrossRef]

42. MacKerell, A.D., Jr.; Feig, M.; Brooks, C.L., III. Extending the treatment of backbone energetics in protein force fields: Limitations of gas-phase quantum mechanics in reproducing protein conformational distributions in molecular dynamics simulations. J. Comput. Chem. 2004, 25, 1400-1415. [CrossRef]

43. MacKerell, A.D., Jr.; Bashford, D.; Bellott, M.; Dunbrack, R.L.; Evanseck, J.D.; Field, M.J.; Fischer, S.; Gao, J.; Guo, H.; Ha, S.; et al. All-atom empirical potential for molecular modeling and dynamics Studies of proteins. J. Phys. Chem. B 1998, 102, 3586-3616. [CrossRef]

44. Bjelkmar, P.; Larsson, P.; Cuendet, M.A.; Bess, B.; Lindahl, E. Implementation of the CHARMM force field in GROMACS: Analysis of protein stability effects from correction maps, virtual interaction sites, and water models. J. Chem. Theory Comput. 2010, 6, 459-466. [CrossRef]

45. Li, P.; Roberts, B.P.; Chakravorty, D.K.; Merz, K.M., Jr. Rational Design of Particle Mesh Ewald Compatible Lennard-Jones Parameters for +2 Metal Cations in Explicit Solvent. J. Chem. Theory Comput. 2013, 9, 2733-2748. [CrossRef]

46. Stote, R.H.; Karplus, M. Zinc Binding in Proteins and Solution: A Simple but Accurate Nonbonded Representation. Proteins 1995, 23, 12-31. [CrossRef]

47. Foote, J.W.; Delves, H.T. Determination of non-protein-bound zinc in human serum using ultrafiltration and atomic absorption spectrometry with electrothermal atomisation. Analyst 1988, 113, 911-915. [CrossRef] 
48. Forman, D.T.; Lorenzo, L. Ionized Calcium: Its significance and Clinical Usefulness. Ann. Clin. Lab. Sci. 1991, 21, 297-304.

49. Berendsen, H.J.C.; Postma, J.P.M.; van Gunsteren, W.F.; DiNola, A.; Haak, J.R. Molecular dynamics with coupling to an external bath. J. Chem. Phys. 1984, 81, 3684-3690. [CrossRef]

50. Bussi, G.; Donadio, D.; Parrinello, M. Canonical Sampling through Velocity Rescaling. J. Chem. Phys. 2007, 126, 014101. [CrossRef]

51. Hess, B.; Bekker, H.; Berendsen, H.J.C.; Fraaije, J.G.E.M. LINCS: A Linear Constraint Solver for molecular simulations. J. Comput. Chem. 1997, 18, 1463-1472. [CrossRef]

52. Hess, B. P-LINCS: A Parallel Linear Constraint Solver for Molecular Simulation. J. Chem Theory Comput. 2008, 4, 116-122. [CrossRef]

53. Essmann, U.; Perera, L.; Berkowitz, M.L.; Darden, T.; Lee, H.; Pedersen, L.G. A smooth particle mesh Ewald method. J. Chem. Phys. 1995, 103, 8577-8592. [CrossRef]

54. Parrinello, M.; Rahman, A. Polymorphic Transitions in Single Crystals: A New Molecular Dynamics Method. J. Appl. Phys. 1981, 52, 7182-7190. [CrossRef]

55. White, A.D.; Keefe, A.J.; Ella-Menye, J.R.; Nowinski, A.K.; Shao, Q.; Pfaendtner, J.; Jiang, S. Free energy of solvated salt bridges: A simulation and experimental study. J. Phys. Chem. B 2013, 117, 7254-7259. [CrossRef]

56. Nguyen, B.L.; Pettitt, B.M. Effects of Acids, Bases, and Heteroatoms on Proximal Radial Distribution Functions for Proteins. J. Chem. Theory Comput. 2015, 11, 1399-1409. [CrossRef]

57. Mu, Y.; Nguyen, P.H.; Stock, G. Energy landscape of a small peptide revealed by dihedral angle principal component analysis. Proteins 2005, 58, 45-52. [CrossRef]

58. Altis, A.; Nguyen, P.H.; Hegger, R.; Stock, G. Dihedral Angle Principal Component Analysis of Molecular Dynamics Simulations. J. Chem. Phys. 2007, 126, 216-225. [CrossRef]

59. Ligges, U.; Mächler, M. Scatterplot3d-An R Package for Visualizing Multivariate Data. J. Stat. Softw. 2003, 8, 1-20. [CrossRef]

60. Akima, H.; Gebhardt, A.; Petzold, T.; Maechler, M. akima: Interpolation of Irregularly and Regularly Spaced Data. Available online: https://CRAN.R-project.org/package=akima (accessed on 2 January 2019).

61. Sarkar, D.; Andrews, F. latticeExtra: Extra Graphical Utilities Based on Lattice. Available online: https: //CRAN.R-project.org/package=latticeExtra (accessed on 2 January 2019).

62. Tan, P.-N.; Steinbach, M.; Kumar, V. Cluster Analysis: Basic Concepts and Algorithms in Introduction to Data Mining, 2nd ed.; Pearson Press: New York, NY, USA, 2005; Chapter 8; pp. 487-568. ISBN 978-0321321367.

63. Tan, P.-N.; Steinbach, M.; Kumar, V. Cluster Analysis: Additional Issues and Algorithms in Introduction to Data Mining, 2nd ed.; Pearson Press: New York, NY, USA, 2005; Chapter 9; pp. 569-650. ISBN 978-0321321367.

64. Rousseeuw, P.J. Silhouettes: A graphical aid to the interpretation and validation of cluster analysis. J. Comput. Appl. Math. 1987, 20, 53-56. [CrossRef]

65. Thinsungnoena, T.; Kaoungkub, N.; Durongdumronchaib, P.; Kerdprasopb, K.; Kerdprasopb, N. The Clustering Validity with Silhouette and Sum of Squared Errors. In Proceedings of the 3rd International Conference on Industrial Application Engineering, Kitakyushu, Japan, 28-31 March 2015; Volume 3, pp. $44-51$. [CrossRef]

66. Romanowska, J.; Nowínski, K.S.; Trylska, J. Determining Geometrically Stable Domains in Molecular Conformation Sets. J. Chem. Theory Comput. 2012, 8, 2588-2599. [CrossRef]

67. Grant, B.J.; Rodrigues, A.P.; El Sawy, K.M.; McCammon, J.A.; Caves, L.S. Bio3d: An R Package for the Comparative Analysis of Protein Structures. Available online: https://CRAN.R-project.org/package=bio3d (accessed on 2 January 2019).

68. Grant, B.J.; Rodrigues, A.P.; El Sawy, K.M.; McCammon, J.A.; Caves, L.S. Bio3d: An R package for the comparative analysis of protein structures. Bioinformatics 2006, 22, 2695-2696. [CrossRef]

69. Pearson, K. Notes on regression and inheritance in the case of two parents. Proc. R. Soc. Lond. 1895, 58, 240-242. [CrossRef]

70. Hünenberger, P.H.; Mark, A.E.; van Gunsteren, W.F. Fluctuation and cross-correlation analysis of protein motions observed in nanosecond molecular dynamics simulations. J. Mol. Biol. 1995, 252, 492-503. [CrossRef]

71. Kumari, R.; Kumar, R.; Lynn, A. g_mmpbsa: A GROMACS tool for high-throughput MMPBSA calculations. J. Chem. Inf. Model. 2014, 54, 1951-1962. [CrossRef]

72. Baker, N.A.; Sept, D.; Joseph, S.; Holst, M.J.; McCammon, J.A. Electrostatics of nanosystems: Application to microtubules and the ribosome. Proc. Natl. Acad. Sci. USA 2001, 98, 10037-10041. [CrossRef] 
73. Sitkoff, D.; Sharp, K.A.; Honig, B. Accurate Calculation of Hydration Free-Energies Using Macroscopic Solvent Models. J. Phys. Chem. 1994, 98, 1978-1988. [CrossRef]

74. Sun, A.; Yan, Y.N.; Yang, M.; Zhang, J.Z.H. Interaction entropy for protein-protein binding. J. Chem. Phys. 2017, 146, 124124. [CrossRef]

75. Tukey, J.W. Exploratory Data Analysis; Addison-Wesley: Reading, MA, USA, 1977; p. 688. ISBN 0-201-07616-0. 